\title{
Dentate spikes and external control of hippocampal function
}

Dvorak, D. ${ }^{1}$, Chung, A. ${ }^{1,{ }^{*}}$, Park E. H. ${ }^{1}$, Fenton, A. A. ${ }^{1,2}$

${ }^{1}$ Center for Neural Science, New York University, New York, NY

${ }^{2}$ Neuroscience Institute at the NYU Langone Medical Center, New York, NY

* Massachusetts General Hospital, Boston, MA (current affiliation)

Author for Correspondence:

André Fenton

Center for Neural Science, New York University, 4 Washington Place, New York, NY

(212) 9926573

afenton@nyu.edu 


\begin{abstract}
Mouse hippocampus CA1 place-cell discharge typically encodes current location but during slow gamma dominance $\left(\mathrm{SG}_{\mathrm{dom}}\right)$, when slow gamma oscillations $(30-50 \mathrm{~Hz})$ dominate midfrequency gamma oscillations $(70-90 \mathrm{~Hz})$ in CA1 local field potentials, CA1 discharge switches to represent distant recollected locations. We report that dentate spike type $2\left(D S_{M}\right)$ events initiated by $\mathrm{MECII} \rightarrow \mathrm{DG}$ inputs promote $\mathrm{SG}_{\mathrm{dom}}$ and change excitation-inhibition coordinated discharge in DG, CA3, and CA1, whereas type $1\left(D S_{L}\right)$ events initiated by LECII $\rightarrow$ DG inputs do not. Just before $S_{\text {dom, }}$ LECIl-originating slow gamma oscillations in dentate gyrus and CA3originating slow gamma oscillations in CA1 phase and frequency synchronize at the $\mathrm{DS}_{\mathrm{M}}$ peak when discharge within DG and CA3 increases to promote excitation-inhibition cofiring within and across the $D G \rightarrow C A 3 \rightarrow C A 1$ pathway. This optimizes discharge for the 5-10 ms DG-to-CA1 neuro-transmission that coincides with $\mathrm{SG}_{\mathrm{dom}}$. $\mathrm{DS} \mathrm{S}_{\mathrm{M}}$ properties identify extrahippocampal control of $\mathrm{SG}_{\mathrm{dom}}$, and a cortico-hippocampal mechanism that switches between memory-related modes of information processing.
\end{abstract}




\section{Introduction}

The hippocampus is critical for long-term memory storage and use, requiring that neural discharge represent both what has occurred and what is happening. How do multifunction neural networks like hippocampus accomplish mutually incompatible tasks like recollecting the past and encoding the present? One possibility is that separate neural circuits operate in parallel to perform each information processing task, but this does not appear to be the case for hippocampus. Rather, in hippocampus the same populations of excitatory and inhibitory neurons are organized such that network discharge patterns, sometimes called cell assemblies (Harris et al., 2003; Hebb, 1949) rapidly switch between different information processing modes, often in a winner-take-all fashion during vicarious-trial-and-error and other choice behaviors (Colgin, 2015; Johnson and Redish, 2007; Kelemen and Fenton, 2010; Kelemen and Fenton, 2013; Kelemen and Fenton, 2016; Papale et al., 2016; Pastalkova et al., 2008; van Dijk and Fenton, 2018; Wu et al., 2017). Indeed, we first reported variability in the discharge of hippocampus place cells that was so extreme it was incompatible with these cells merely signaling the current location within a single cognitive map (Fenton and Muller, 1998; Jackson and Redish, 2007; Olypher et al., 2002a, b) and we went on to show that this variability could be explained as multiple spatial representations during tasks with purposeful behaviors that were directed to specific places (Fenton et al., 2010; Kelemen and Fenton, 2010; Kelemen and Fenton, 2013; Kelemen and Fenton, 2016). In an alternation task, such variability was organized as place representations that alternate within sequences of $\sim 8 \mathrm{~Hz}$ theta oscillations, perhaps reflecting planning between which upcoming alternatives to choose (Kay et al., 2020). We previously reported that position-representing CA1 ensemble spike trains switch between representing the current, local position and distant specific places, which during an active place avoidance task represented recollected locations of prior foot-shock (Dvorak et al., 2018). Specifically, CA1 discharge switched to signaling distant places during slow-gamma dominance 


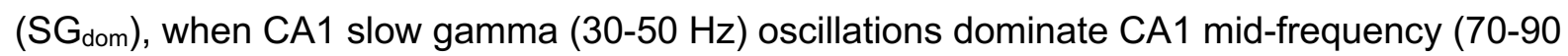

$\mathrm{Hz}$ ) gamma oscillations. Now that it is established that such network transitions occur to change hippocampal cognitive information processing, it is essential to understand how such transitions might occur in hippocampus as well as other cognitive networks that transiently switch information processing modes in circumstances that are physically unchanged.

\section{Results}

Slow gamma dominance in the CA1 LFP switches CA1 place discharge to represent recollection of distant locations

Well-trained mice on the rotating place avoidance arena make evasive movements away from the advancing shock zone, as illustrated in the upper portion of Figure $1 \mathrm{~A}$. This behavior demonstrates the mice recollect locations where they were previously shocked. Approximately 1-2 seconds before running away to avoid the location of shock, we observe slow gamma dominance $\left(S G_{d o m}\right)$ in the CA1 LFP, that is the result of a relatively increased rate of slow gamma $(30-50 \mathrm{~Hz})$ oscillations and a decreased rate of mid-frequency gamma $(70-90 \mathrm{~Hz})$ oscillations (Fig. 1A, lower). The likelihood of $\mathbf{S G}_{\text {dom }}$ is elevated before mice express active avoidance, with the peak $1.75 \mathrm{~s}$ before, when the mouse is often inactive (Fig. 1A, B). In contrast, $S G_{\text {dom }}$ is unlikely during the passive approach to the shock zone if the mouse will fail to avoid the approaching shock zone and rather runs away to escape after receiving a shock (Fig. 1B). Such failed avoidances are rare, and most likely occur because the mouse did not recollect the location of shock. Place cells with firing fields in the vicinity of the shock, discharge transiently for about 500 ms during $\mathrm{SG}_{\mathrm{dom}}$, despite the mouse not being in the vicinity of shock, which can be seen in a single 5-s example (Fig. 1C), in the group data (Fig. 1D), and is confirmed by analysis of place cell overdispersion (Fig. S1A-D). Conversely, place cell ensemble discharge continues to decode to the current location when mice fail to avoid the shock (Dvorak et al., 2018). Because CA1 ensemble discharge can transiently switch from 
signaling current location to signaling a distant, recollected location, we wondered which network mechanisms can cause this switch between information processing modes (Fig. 1E)? One way to switch between multiple mutually-exclusive tasks is to organize the network so that its intrinsic excitation-inhibition dynamics are so balanced that the network spontaneously transitions between multiple information processing modes through intrinsic winner-take-all mechanisms (Fig. 1E, F upper; de Almeida et al., 2009; Rolls and Treves, 1998). In the alternative scenario explored here, $\mathrm{SG}_{\mathrm{dom}}$-associated switches of the $\mathrm{CA} 1$ information processing mode are controlled by discrete events in the perforant path tri-synaptic input from the entorhinal cortex (Fig. 1F, lower).
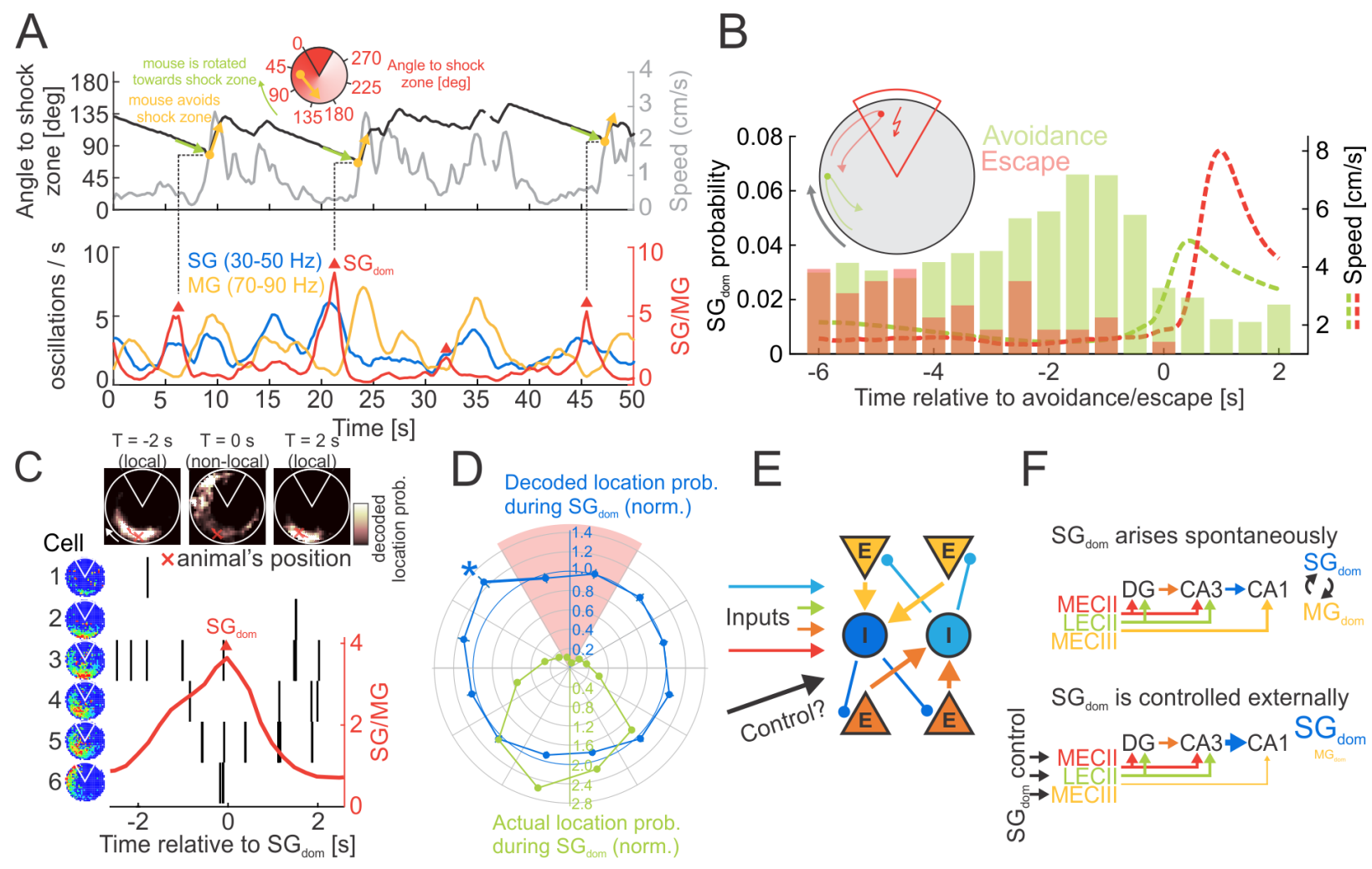

F

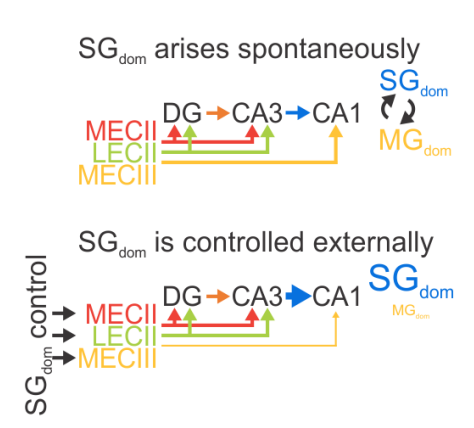

Figure $1 . S_{\text {dom }}$ is a biomarker of memory recollection. A) Avoidances (yellow vectors) mark evasive movements with preceding stillness (green vectors) away from the shock zone without receiving shock. $S G_{\text {dom }}$ detected as local maxima (red triangles) in the ratio (red line) of rates of CA1 slow (blue; 30-50 Hz) and mid-frequency (yellow; 70-90 Hz) gamma oscillations, precede 
avoidance movements by 1-2 seconds. B) $S_{\text {dom }}$ probability histogram before avoidance (green; success $=$ no shock) and escape (red; failure $=$ shocked). C) CA1 single unit discharge (vertical black lines) of a 6 -cell ensemble around a $S_{\text {dom }}$ event (red triangle). The firing rate map of each cell is shown on the left. The 2-D posterior probability distributions computed using Bayesian decoding are shown at the top overlayed with the mouse's 5-s track (red line) and current location (red cross). During $\mathrm{SG}_{\mathrm{dom}}$, the otherwise accurate Bayesian posterior decodes to the shock zone, away from the mouse's current location. D) Normalized circular probability distributions of mouse locations (green) and decoded locations (blue) during SG $_{\text {dom }}$ (normalization using non-SG ${ }_{\text {dom }}$ events). * significant deviation from 1 (t $t_{778}=3.10, p=0.002$, Bonferroni's correction). While $S_{\text {dom }}$ happens predominantly when the mouse is opposite the shock zone (green), discharge during $S_{G_{d o m}}$ decodes to locations of shock zone entries (blue). E) Schematic network with winner-take-all dynamics, composed of excitatory (E) and inhibitory (I) neurons, excitatory inputs and a possible external control signal. F) Two hypotheses for hippocampal information processing control (upper) intrinsic, intrahippocampal and (lower) extrinsic, extrahippocampal control. Data in B and D from 2 mice.

Identifying the two types of dentate spike originating from distinct perforant path inputs

CA1 slow gamma originates in CA3 (Lasztoczi and Klausberger, 2014, 2016; Schomburg et al., 2014), motivating us to seek evidence of extrahippocampal control signals in the perforant path projection from ECIl to dentate gyrus (DG). We examine dentate spikes (DS), the underinvestigated, large amplitude, short duration field potentials that localize to DG (Fig. 2A; Fig. S1E). They result from entorhinal activation; dentate spikes disappear after bilateral removal of entorhinal cortex (Bragin et al., 1995). Similar to sharp-wave ripples (SWR), dentate spikes are synchronized across hemispheres (Bragin et al., 1995; Headley et al., 2017) but in contrast to SWR, DS are thought to cause a synchronized inhibition of granule cells and downstream CA3 and CA1 networks (Fig. 2A left; Penttonen et al., 1997). 
Using current source density (CSD) analysis we classify two types of DS events (Fig. 2B; Star Methods) as $D S_{L}$ (current sink in outer molecular layers of $D G$ ) and $D S_{M}$ (current sink in middle molecular layers of DG), corresponding to types 1 and 2 identified in rat (Bragin et al., 1995) and mouse (Buzsaki et al., 2003). Localization of the outer and middle molecular layers of DG, is confirmed by the average CSD of the evoked response to stimulating the medial perforant path (MPP; Fig. $2 \mathrm{C}$, right). The $\mathrm{DS}_{\mathrm{L}}$ amplitude is larger than $\mathrm{DS}_{\mathrm{M}}\left(\right.$ Fig. $2 \mathrm{D}$; paired $\mathrm{t}_{8}=2.87, \mathrm{p}=$ 0.02 ) while $D S_{M}$ width is greater than $D S_{L}$ (paired $t_{8}=8.56, p=10^{-5}$ ). $D S_{L}$ before $D S_{M}$ is more likely than vice versa (Fig. $2 E$; paired $t_{8}=5.61, p=10^{-4}$ ). The average CSDs of $D S_{L}$ and $D S_{M}$ during stillness (speed $<2 \mathrm{~cm} / \mathrm{s}$ ) and running (speed $>3 \mathrm{~cm} / \mathrm{s}$ ) do not visibly differ (Fig. 2F). Rates of $D S_{L}$ and $D S_{M}$ events are not different, but they are differentially modulated by speed

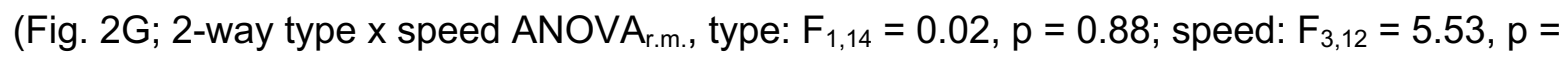
0.013; interaction: $F_{3,12}=5.26, p=0.015$, post-hoc tests: $D S_{M}>D S_{L}$ at the greatest speeds of 6$8 \mathrm{~cm} / \mathrm{s}$ ). $D S_{L}$ and $D S_{M}$ are distinct in origin and morphology but not independent, are modulated by behavior, and $D S_{M}$ is more likely to follow $D S_{L}$. 


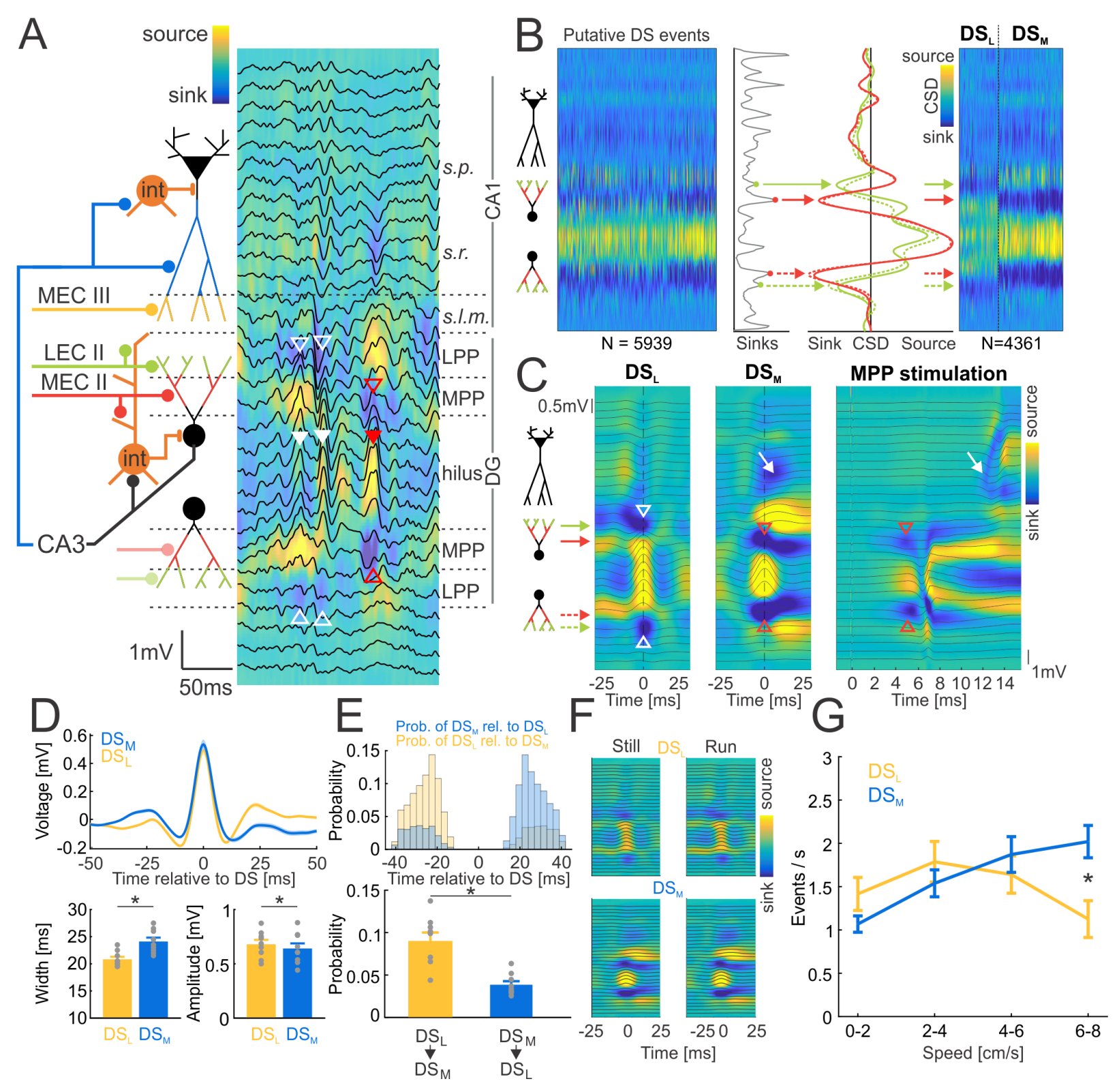

Figure 2. CSD analysis classifies two types of dentate spikes with distinct anatomical, temporal, and behavioral properties. A) $D S_{L}$ (full white arrowheads) is identified by a pair of current-source-density (CSD) sinks in the outer molecular layers of DG (empty white arrowheads) at the LECII projection termination. $\mathrm{DS}_{\mathrm{M}}$ (full red arrowheads) is identified by a pair of CSD sinks in the middle molecular layers of DG (empty red arrowheads) at the MECII projection termination. Background color represents CSD. Black traces represent the LFP. Schematic (left) illustrating hypothesized components of dentate spike generation and 
mechanism of CA1 SG dom control. B) CSD of putative DS events (left) and histogram of local minima in CSD profiles (middle) shows peaks aligned with pairs of sink bands in the outer (solid green and dashed green traces) and middle (solid red and dashed red traces) molecular layers. CSD profiles (right) of the two types of DS events. C) Average CSDs of DS $S_{L}$ (left) and DS $M$ (middle), with $\mathrm{DS}_{\mathrm{L}}$ sinks at outer molecular layers (white empty arrowheads) and $\mathrm{DS}_{\mathrm{M}}$ sinks at middle molecular layers (red empty arrowheads). The CSD of the evoked response to medial perforant path (MPP) stimulation (right), evokes sinks (red empty arrowheads) at the same locations of the $\mathrm{DS}_{\mathrm{M}}$ sinks. $\mathrm{A} \sim 6 \mathrm{~ms}$ latency sink at CA1 stratum radiatum occurs after both the MPP evoked response and $D S_{M}\left(\right.$ white arrow), but not after DS $S_{L}$. D) Average LFP of DS $S_{L}$ (yellow) and $\mathrm{DS}_{\mathrm{M}}$ (blue) with their width and amplitude comparisons (bottom). E) Histograms illustrate that $D S_{M}$ often follows $D S_{L}$ (top) and the probability of observing $D S_{L} \rightarrow D S_{M} v s$. $D_{M} \rightarrow D S_{L}$ pairs (bottom). F) Average CSDs of $D S_{L}$ (top) and $D S_{M}$ (bottom) during stillness (speed $<2 \mathrm{~cm} / \mathrm{s}$; left) and running (speed $>3 \mathrm{~cm} / \mathrm{s}$; right). G) Relationship between DS rates and running speed. Averages \pm S.E.M. are plotted.

\section{Dentate spikes modulate oscillatory activity in CA1}

We investigate whether $D S_{L}$ and $D S_{M}$ influence the CA1 oscillatory activity components of $\mathrm{SG}_{\text {dom. }}$. Analysis of CA1 oscillatory dynamics using LFP spectral power is confounded by the spectral leakage of DS events in the $30-50 \mathrm{~Hz}$ range (Fig. 3A). Accordingly, we use independent component analysis (ICA; Star Methods), which identifies two independent components (IC) in the CA1 LFP below $100 \mathrm{~Hz}$ (Fig. 3B), a CA3-originating, stratum radiatum-localized slow gamma IC (SG ${ }_{S R}$; mean frequency $34.1 \pm 3.0 \mathrm{~Hz}$; Fig. 3C, left; Fig. S2A) and a MECIIIoriginating, stratum lacunosum moleculare-localized mid-frequency gamma IC (MG $\mathrm{M}_{S L M}$; mean frequency $68.9 \pm 3.4 \mathrm{~Hz}$; Fig. 3C, right; Fig. S2A). 
If dentate spikes modulate CA1 oscillatory activity, they should systematically co-occur with $S G_{S R}$ and $M G_{S L M}$ oscillatory events. $S G_{S R}$ oscillatory events occur close to the theta trough $\left(339.2^{\circ} \pm 71.4^{\circ}\right)$, whereas the $M G_{S L M}$ oscillatory events occur close to the theta peak $\left(220.5^{\circ} \pm\right.$ 59.9; Fig. 3D top), in agreement with prior work (Fernandez-Ruiz et al., 2017; Lasztoczi and Klausberger, 2014). DS $S_{M}$ events occur at the theta trough, coinciding with $S_{S R}$ oscillatory events $\left(344.0^{\circ} \pm 59.8\right.$; Watson-Williams multi-sample test $\left.F_{1,15}=0.19, p=0.67\right)$, whereas the $D S_{L}$ events occur close to the theta peak, coinciding with the $M_{S L M}$ oscillatory events $\left(233.6^{\circ} \pm\right.$ 71.2 ${ }^{\circ}$; Watson-Williams multi-sample test $F_{1,15}=3.48, p=0.08$; Fig. 3D).

The theta phase alignment of $D S_{L}$ and $M G_{S L M}$ events and the distinct phase alignment of $D S_{M}$ and $\mathrm{SG}_{S R}$ events might be expected if DS events control CA1 gamma events, motivating us to determine whether DS events also influence locally-generated CA1 gamma power. We compute $D S_{L}-$ and $D S_{M}$-triggered IC power profiles by averaging the z-scored wavelet spectrogram computed from identified ICs across $25-45 \mathrm{~Hz}$ for $\mathrm{SG}_{S R}$ and $45-85 \mathrm{~Hz}$ for $\mathrm{MG}_{S L M}$ (Fig. 3E). To evaluate if the potential influence of the DS events on the CA1 ICs is distinct from the theta modulation of IC power (see Fig. 3D), we also compare control power profiles triggered by random events that have the same theta phase distribution as the corresponding DS events, but only a chance association with the DS events. Data from 8 of 9 mice are analyzed because one mouse did not have CA1 electrode coverage. $M_{S L M}$ is increased $36 \%$ at the $D S_{\llcorner}$peak compared to random (paired $t_{7}=6.82, p=10^{-4}$ ), while $S G_{S R}$ is not (paired $t_{7}=0.35, p=0.7$; Fig. $3 E$, left). In contrast, $S G_{S R}$ is increased $67 \%$ at the peak of $D S_{M}$ compared to random (paired $t_{7}$ $=5.0, p=0.002$ ), while $M G_{S L M}$ is decreased during $D S_{M}$ (paired $t_{7}=2.68, p=0.03 ;$ Fig. $3 E$, right).

To examine the co-occurrence of the DS and CA1 gamma oscillatory events, we randomly pick 1000 times from each 30-min recording and assess whether $M_{S L M}$ or $S_{S R}$ occurs within a 50- 
ms coincidence interval of $D S_{L}$ or $D S_{M}$. The probability of observing $S G_{S R}$ is greater if $D S_{M}$ is observed [Fig. 3F, left; $F_{3,31}=9.59, p=10^{-4}, p\left(S G_{S R} \mid D S_{M}\right)>p\left(S G_{S R} \mid D S_{L}\right)=p\left(S G_{S R} \mid\right.$ nonDS $\left._{M}\right)$ $=p\left(S G_{S R} \mid\right.$ nonDS $\left.\left.S_{L}\right)\right]$ while the probability of observing $M G_{S L M}$ is greater if a $D S_{L}$ event is observed [Fig. 3F, right; $F_{3,31}=7.31, p=10^{-4}, p\left(M G_{S L M} \mid D S_{L}\right)>p\left(M G_{S L M} \mid D S_{M}\right)=p\left(M G_{S L M} \mid\right.$ $\left.\left.\operatorname{nonDS}_{L}\right)=p\left(M G_{S L M} \mid \operatorname{nonDS}_{M}\right)\right]$.
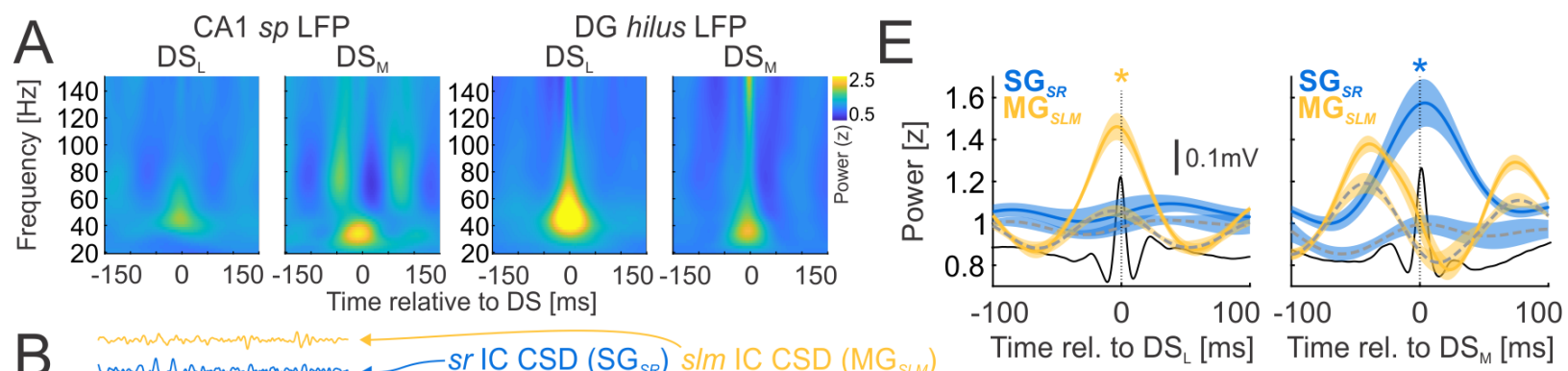

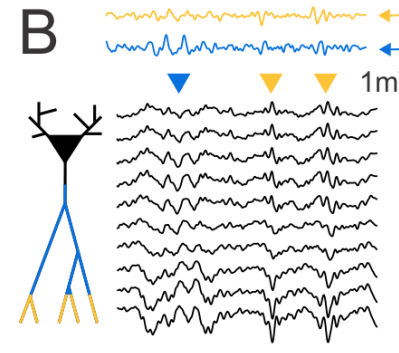

C
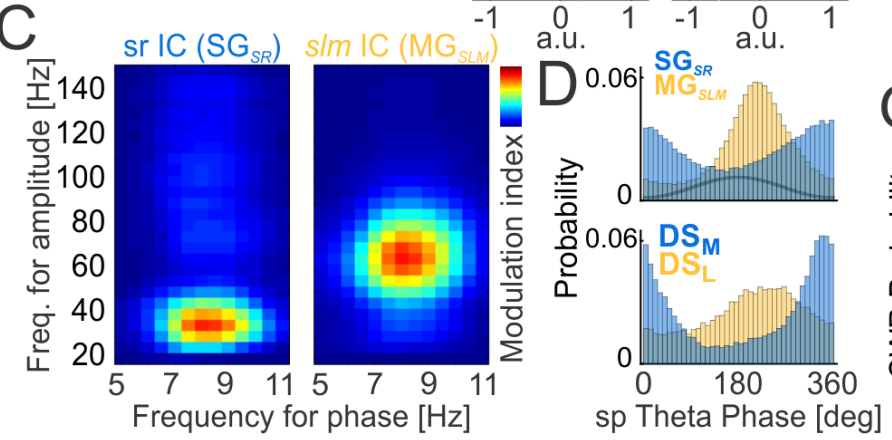
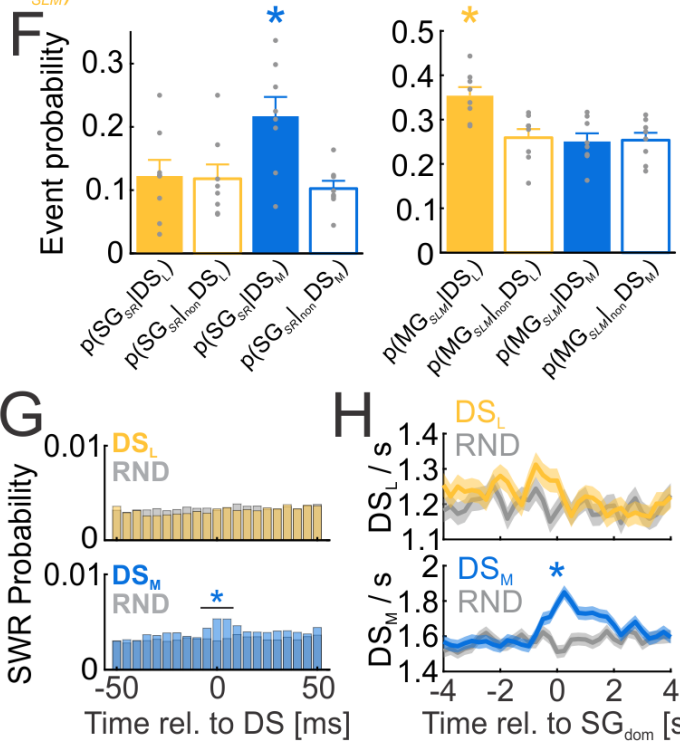

Figure 3. Dentate spikes modulate $\mathbf{S G}_{\text {dom }}$ and gamma oscillatory activity in CA1 A)

Average wavelet spectrogram of CA1 stratum pyramidale LFP (left) and DG hilar LFP (right), triggered by $D S_{L}$ and $D S_{M}$ events reveal volume-conducted DS spectral leakage in the $30-50 \mathrm{~Hz}$ range, with higher peak frequency associated with narrower $D S_{\llcorner}$events and lower peak frequency associated with wider $\mathrm{DS}_{\mathrm{M}}$ events, as expected (compare with Fig. 2D). B) ICA decomposition of CA1 LFPs identifies two independent components (IC) $<100 \mathrm{~Hz}$ that correspond to stratum radiatum dendritic input $\left(\mathrm{SG}_{S R}, \mathrm{CA} 1\right.$ slow gamma, blue), and stratum 
lacunosum moleculare dendritic input ( $\mathrm{MG}_{S L M}, \mathrm{CA} 1$ mid-frequency gamma, yellow). Arrowheads mark $\mathrm{SG}_{S R}$ (blue) and $\mathrm{MG}_{S L M}$ (yellow) oscillatory events in the LFP. The CSDs of ICA voltage loadings (right) show a $\mathrm{SG}_{S R}$ sink in stratum radiatum and a $\mathrm{MG}_{S L M}$ sink in stratum lacunosum moleculare. C) Comodulograms between the phase of CA1 stratum pyramidale theta $(5-11 \mathrm{~Hz})$ and the $\mathrm{SG}_{S R}$ and $\mathrm{MG}_{S L M}$ gamma amplitudes in the $20-150 \mathrm{~Hz}$ frequency range show slow gamma peaks for $S_{S R}$ and mid-frequency gamma peaks for $\mathrm{MG}_{S L M}$. D) Theta phase (black line) distribution of $\mathrm{SG}_{S R}$ (blue) and $\mathrm{MG}_{S L M}$ (yellow) oscillatory events (top) compared to theta phase distribution of $\mathrm{DS}_{\mathrm{M}}$ (blue) and $\mathrm{DS} \mathrm{S}_{\mathrm{L}}$ (yellow) events (bottom). E) Power averages of $\mathrm{SG}_{S R}$ (blue) and $M G_{S L M}$ (yellow) centered on $D S_{L}$ (left) and $D S_{M}$ (right). $T=0$ marks the DS peak. Gray dashed lines show IC power profiles at random times sampled from the same theta phase distributions as the corresponding $D S_{L}$ and $D S_{M}$ events. Black lines are $D S_{L}$ and $D S_{M}$ event averages. F) Coincidence of the DS and IC oscillatory events detected from SG $_{S R}$ (left) and $M G_{S L M}$ (right) at random times. G) SWR probability distribution relative to $D S_{L}$ (top), $D S_{M}$ (bottom) and random times (gray) during stillness. $H$ ) Rates of $D S_{L}$ (top) and $D S_{M}$ (bottom) centered at $\mathrm{SG}_{\text {dom }}$ (color) and randomly selected times (gray). Averages \pm S.E.M. are plotted.

Since $\mathrm{DS}_{\mathrm{M}}$ increases the power of CA3-originating $\mathrm{SG}_{S R}$ (Fig. 3E) and dentate spikes co-occur with CA3-originating sharp wave ripples (SWR; Bragin et al., 1995), we computed the probability of a SWR within $\pm 50 \mathrm{~ms}$ of $\mathrm{DS} \mathrm{L}_{\mathrm{L}}, \mathrm{DS}_{\mathrm{M}}$, and random events during stillness (speed $<2 \mathrm{~cm} / \mathrm{s}$; Fig. 3G). SWR probability is increased \pm 10 ms of the $D S_{M}$ peak but not $D S_{L}$ (Fig. 3G; One sample test for proportions: $p\left(S W R \mid D S_{L}\right)=0.012, z=0.71, p=0.3 ; p\left(S W R \mid D S_{M}\right)=0.018, z=13.20$, $\left.p=10^{-39}\right)$.

If $D S_{M}$ controls $C A 1$ information processing mode, these findings of DS modulation of CA1 gamma predict that $\mathrm{DS}$ (but not $D S_{\mathrm{L}}$ ) promotes $C A 1 \mathrm{SG}_{\mathrm{dom}}$. We evaluated this prediction using 
$S G_{d o m}$ events collected during place avoidance behavior, where $S_{\text {dom }}$ events identify recollection (Fig. 1). The rate of $D S_{M}$ but not $D S_{L}$ events is elevated at the time of $S G_{d o m}$ (Fig. $\left.3 H ; D S_{L}: t_{5255}=1.81, p=0.07 ; D S_{M}: t_{5255}=5.07, p<0.0001\right)$.

Dentate spikes modulate individual cycles of CA1 gamma oscillations, $D S_{M}$ promoting $S_{\text {dom }}$

If $\mathrm{DS}_{\mathrm{M}}$ events control $\mathrm{CA} 1$ information processing by promoting $\mathrm{SG}_{\mathrm{dom}}$, then $\mathrm{DS}_{\mathrm{M}}$ should influence CA1 gamma oscillations with a precision comparable to the $\sim 6 \mathrm{~ms}$ conduction time from dentate gyrus to CA1 (Fig. 2C, white arrows). Because measuring gamma power requires $\sim 100 \mathrm{~ms}$ (3-5 cycles of an oscillatory burst; Figs. 3E, S2C), and spiking is most likely during oscillatory minima (Fig. S2B; Dvorak and Fenton, 2014; Lasztoczi and Klausberger, 2016; Schomburg et al., 2012), we measure discrete oscillatory events with $\sim 15 \mathrm{~ms}$ resolution, as the local minima of oscillatory bursts (Fig. 4A inset; Star Methods). The findings in Fig. 4, data acquired during the place avoidance task, are essentially similar in home-cage data (Fig. S3A).

The probability of observing a $M G_{S L M}$ oscillatory cycle is strongly enhanced $\pm 10 \mathrm{~ms}$ of the $\mathrm{DS} \mathrm{S}_{\mathrm{L}}$ peak (paired $t_{7}=5.43, p=0.001 ;$ Fig $4 A$, left) as well as $15 \mathrm{~ms}$ before and $16 \mathrm{~ms}$ after the $\mathrm{DS} \mathrm{S}_{\mathrm{L}}$ peak, corresponding to a $\mathrm{MG}_{S L M}$ oscillatory frequency of $69 \mathrm{~Hz}$, whereas the probability of observing a $S G_{S R}$ oscillatory cycle remains unchanged during $D S_{\llcorner}$(paired $t_{7}=0.69, p=0.52$;

Fig $4 \mathrm{~A}$, left). In contrast, the probability of observing a $\mathrm{SG}_{S R}$ oscillatory cycle is enhanced $6 \mathrm{~ms}$ after the peak of $D S_{M}$, corresponding to the transmission time between DG and CA1, which is primarily influenced by the CA3 $\rightarrow$ CA1 synaptic delay (Mizuseki et al., 2012; Fig 4A, right; paired $\left.t_{7}=4.52, p=0.003\right)$. The probability of a $S G_{S R}$ oscillatory cycle is also enhanced 24 ms before and $33 \mathrm{~ms}$ after the $\mathrm{DS}_{\mathrm{M}}$ peak corresponding to a $\mathrm{SG}_{S R}$ oscillatory frequency of $34 \mathrm{~Hz}$, whereas the probability of observing a $M G_{S L M}$ oscillatory cycle is not different (Fig. $4 \mathrm{~A}$ right; paired $\mathrm{t}_{7}=$ $0.79, p=0.45 ;)$. There is a non-oscillatory increase of the $M_{S L M}$ oscillatory cycle probability 30 - 
$50 \mathrm{~ms}$ before $\mathrm{DS}_{\mathrm{M}}\left(\right.$ Fig 4A, right; paired $\left.t_{7}=3.80, p=0.007\right)$ and a reduced probability of observing a $\mathrm{MG}_{S L M}$ oscillatory cycle $30-50 \mathrm{~ms}$ after $\mathrm{DS}_{\mathrm{M}}\left(\right.$ Fig $4 \mathrm{~A}$, right; paired $\mathrm{t}_{7}=7.39, \mathrm{p}=10^{-4}$ ).

The consequences of MPP manipulations are not straightforward (Brun et al., 2002; Garner et al., 2012; Kanter et al., 2017; Miao et al., 2015; Schlesiger et al., 2018), which was confirmed by chemogenetic silencing, electrical stimulation of MPP, and anesthesia (Fig. S4). Consequently, to rigorously test the hypothesis that $\mathrm{DS}_{\mathrm{M}}$ promotes $\mathrm{SG}_{\mathrm{dom}}$, we examine whether spontaneously strong and weak $D S_{M}$ events differentially promote $S G_{\text {dom. }}$. Because $D S_{M}$ can both increase the likelihood of $S G_{S R}$ and attenuate the likelihood of $M G_{S L M}$ to promote $S G_{d o m}$, $D S_{M}$ were classified according to their prominence (Fig. 4B) and independently, by the $\sim 10 \mathrm{~ms}$ post-DS $\mathrm{M}_{\mathrm{M}}$ CSD source that suggests increased inhibition, corresponds to the DG $\rightarrow$ CA1 transmission time, and localizes to the vicinity of the hippocampal fissure and CA1 s/m (red rectangle in Fig. 4B). Because the s/m CSD source accounts for only $8 \%$ of the variance in $D S_{M}$ prominence (Fig. $4 C$, $\left.D ; r^{2}=0.084, p<0.0001\right)$, we used both features to evaluate the causal predictions that 1) DS events with a large prominence will increase $S G_{S R}$ and 2) that $D S_{M}$ events with a large s/m CSD source will decrease $M G_{S L M}$, each promoting $S_{\text {dom }}$.

The probability of observing $\mathrm{SG}_{S R}$ and $\mathrm{MG}_{S L M}$ oscillatory cycles was computed in relation to the $10 \%$ of $D S_{M}$ with the highest and lowest prominence, DURING $\pm 10 \mathrm{~ms}$ of the $\mathrm{DS}_{\mathrm{M}}$ peak (orange bar in Fig. 4E), 30-50 ms BEFORE (green bar in Fig. 4E), and 30-50 ms AFTER (magenta bar in Fig. 4E). CA1 SG $S_{S R}$ oscillatory cycles were more likely DURING $\left(F_{2,17}=13.10, p=0.0005\right.$, high $>$ low $=$ random $)$ and AFTER $\left(F_{2,17}=12.15, p=0.0007\right.$, high $>$ low $=$ random $)$ the high prominence $D S_{M}$ events compared to the low prominence $D S_{M}$ and random events. These patterns were not observed in relation to $\mathrm{DS}_{\mathrm{L}}$ events (Fig. S3C). CA1 SG $S R$ oscillatory cycles were most probable $\sim 10 \mathrm{~ms}$ after the high and low prominence $\mathrm{DS}_{\mathrm{M}}$ peaks, similar to the $\mathrm{DG} \rightarrow \mathrm{CA} 1$ transmission time. In contrast, $\mathrm{CA} 1 \mathrm{MG}_{S L M}$ oscillatory cycles were more likely BEFORE high prominence $\mathrm{DS}_{\mathrm{M}}\left(\mathrm{F}_{2,17}=8.32, \mathrm{p}=0.004\right.$, high $>$ low $=$ random $)$ but not AFTER 
$\left(F_{2,17}=2.73, p=0.09\right)$. Both the high and low prominence $D S_{L}$ events increased the probability of $M_{S L M}$ oscillatory cycles during $D S_{L}(F i g . S 3 D)$. Together these findings further support the hypothesis that $D S_{M}$ controls $S G_{S R}$ to promote $S_{\text {dom }}$ in $C A 1$.

Complementary patterns of promoting $\mathrm{SG}_{\mathrm{dom}}$ are evident when $\mathrm{DS}_{\mathrm{M}}$ events are categorized as being the $10 \%$ with the largest or smallest s/m CSD source (Fig. 4F). CA1 MGsLM oscillatory cycles were more likely BEFORE $\left(F_{2,17}=9.57, p=0.002\right.$, large $>$ small $=$ random $)$, and less likely DURING $\left(F_{2,17}=16.93, p=0.0001\right.$, small $>$ large $=$ random $)$ and AFTER $\left(F_{2,17}=20.68, p\right.$ $<0.0001$, small $>$ random $>$ large) $D_{M_{M}}$ events with large s/m CSD source (Fig. 4F right). CA1 $S_{S R}$ oscillatory cycles were less likely BEFORE $\left(F_{2,17}=5.39, p=0.017\right.$, small $>$ large $=$ random), DURING $\left(F_{2,17}=11.42, p=0.001\right.$, small $>$ large $>$ random $)$ and AFTER $\left(F_{2,17}=7.00, p\right.$ $=0.0071$, small $>$ large $>$ random) $D_{\mathrm{M}}$ events with large s/m CSD source (Fig. 4F left). Taken together, these analyses confirm the causal predictions that the prominence of DS $S_{M}$ and the amplitude of the associated s/m CSD source together control $\mathrm{SG}_{S R}$ and $\mathrm{MG}_{S L M}$ gamma oscillations to promote $\mathrm{SG}_{\mathrm{dom}}$.
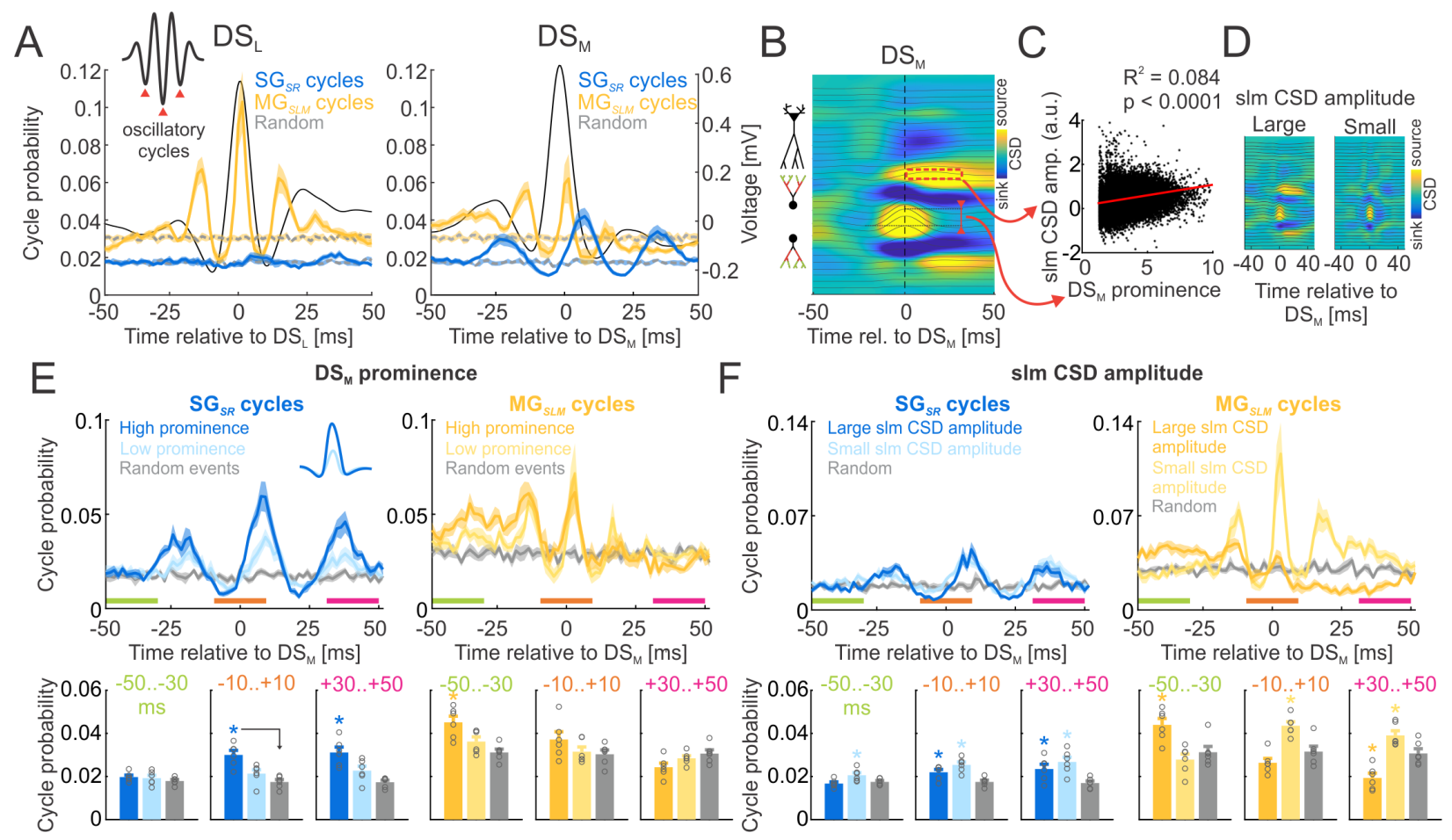
Figure 4. $\mathrm{DS}_{\mathrm{M}}$ controls the oscillatory components of SG dominance. A) Probability of oscillatory cycles (inset, red arrowheads) detected in $\mathrm{SG}_{S R}$ (blue) and $\mathrm{MG}_{S L M}$ (yellow) relative to $\mathrm{DS}_{\mathrm{L}}$ (left), DS $\mathrm{M}_{\mathrm{M}}$ (right) and random events (gray). Average DS waveforms are black. B) CSD indicating $\mathrm{DS}_{\mathrm{M}}$ prominence (red line with reversed arrows) and amplitude of the s/m CSD source that follows $D S_{M}$ (red rectangle). C) Scatter plot of $D S_{M}$ prominence versus the s/m CSD source during $D S_{M}$, with linear fit (red). D) Average $D S_{M}$ CSD of the $10 \%$ largest (left) and smallest (right) $s / m$ CSD sources; the $\mathrm{DS}_{\mathrm{M}}$ prominence is similar. E) Probability of $\mathrm{SG}_{S R}$ cycles (blue; left) and $\mathrm{MG}_{S L M}$ cycles (yellow; right) during the $10 \%$ largest (dark color), and smallest (light color) $D_{\mathrm{M}}(\mathrm{E})$ prominence, $(\mathrm{F})$ s/m CSD source amplitude; random events (gray) and comparisons BEFORE (-50 to $-30 \mathrm{~ms})$, DURING $(-10$ to $+10 \mathrm{~ms})$ and AFTER (30 to $50 \mathrm{~ms})$ the $\mathrm{DS}_{\mathrm{M}}$ events. Averages \pm S.E.M. are plotted.

$D S_{M}$ synchronizes DG and CA1 slow gamma band oscillations

Dentate $D S_{M}$ events increase $C A 3$-originating $S G_{S R}$ to promote $S_{\text {dom }}$, but is CA3 activity under enhanced or reduced DG influence during $D S_{M}$ ? We start by studying the synchrony of DG and CA1 oscillations during DS $S_{\llcorner}$and $D S_{M}$. ICA combined with CSD-based classification of DS events disentangles DS events and DG oscillatory components that both originate in the perforant path projection to DG (Fig. S2D-M; Barth et al., 2018; Fernandez-Ruiz et al., 2013). ICA identified a lateral perforant path (LPP) IC localized to the outer molecular layer DG sinks in the CSD (Fig. S2M) of the ICA voltage loadings and has a slow gamma peak in the CA1 theta phase comodulogram ( $\mathrm{SG}_{\mathrm{LPP}}$; Fig. $5 \mathrm{~A}$, bottom left; mean frequency $43.9 \pm 5.0 \mathrm{~Hz}$ ). The medial perforant path (MPP) IC (Fig. 5A, right) localized to the middle molecular layer DG sinks in the CSD (Fig. S2M) of the ICA voltage loadings and has a mid-frequency gamma peak in the CA1 theta phase comodulogram ( $\mathrm{MG}_{\mathrm{MPP}}$; Fig. 5A, bottom right; mean frequency $71.0 \pm 2.7 \mathrm{~Hz}$ ). While the mean frequency of dentate $S G_{L P P}$ is higher than the mean frequency of the $C A 1 S_{S R}$ 
(paired $t_{6}=3.69, p=0.01$ ), the mean frequencies of dentate $M_{M P P}$ and $C A 1 M G_{S L M}$ do not differ (paired $\left.t_{6}=2.17, p=0.07\right)$.

CA1 theta is used as an intrinsic network time reference to analyze the phase preference of the dentate $S G_{L P P}$ and $M G_{M P P}$ oscillations (Fig. 5B). Dentate $S_{L P P}$ oscillations occur at a late descending phase, close to the theta trough $\left(277.4^{\circ} \pm 74.3^{\circ}\right)$ that precedes both $\mathrm{DS}_{\mathrm{M}}$ (WatsonWilliams multi-sample test $F_{1,14}=6.3, p=0.03$ ) and $S_{S R}$ (Watson-Williams multi-sample test $\left.F_{1,14}=4.5, p=0.05\right)$. Dentate $M G_{M P P}$ occurs close to the theta peak $\left(214.9^{\circ} \pm 59.8^{\circ}\right)$, similar to $D S_{\llcorner}$(Watson-Williams multi-sample test $F_{1,14}=1.9, p=0.19$ ) as well as CA1 MG $S L M$ oscillations (Watson-Williams multi-sample test $\mathrm{F}_{1,14}=0.04, \mathrm{p}=0.83$ ).

Because the DG SG $\mathrm{LPP}_{\text {and }}$ the $\mathrm{CA} 1 \mathrm{SG}_{S R}$ oscillations appear at similar phases of the CA1 theta cycle, and the $\mathrm{DG} M \mathrm{MG}_{\mathrm{MPP}}$ and $\mathrm{CA} 1 \mathrm{MG}_{S L M}$ also appear at similar phases of $\mathrm{CA} 1$ theta (Figs. 3D, 5B), dentate spikes could synchronize the DG and CA1 subfields. We test this possibility by measuring the phase coupling between DG and CA1 slow and mid-frequency gamma oscillations. The frequency-band specific phase locking values (PLV; Lachaux et al., 1999) time-locked to DS events (Fig. 5C; Star Methods) show that the SG $\mathrm{LPP}_{\text {and }} \mathrm{SG}_{S R}$ oscillations are not coupled during $D S_{L}$ (Fig. 5C, top left), whereas $M_{M P P}$ and $M G_{S L M}$ couple during $D S_{L}$ (Fig. 5C, bottom left). In contrast, the $S G_{L P P}$ and $S G_{S R}$ couple strongly after the $D S_{M}$ peak (Fig. 5C, top right), and $\mathrm{MG}_{\mathrm{MPP}}$ and $\mathrm{MG}_{S L M}$ couple $\sim 50 \mathrm{~ms}$ before and $\sim 75 \mathrm{~ms}$ after $\mathrm{DS}_{\mathrm{M}}$ (Fig. 5C, bottom right). The phase interactions are frequency-specific, especially in the case of

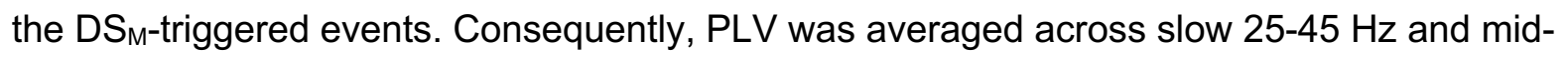
frequency 45-85 Hz gamma bands (Fig. 5D), and to evaluate whether or not any DS-related phase coupling between the DG and CA1 gamma oscillations is simply a result of the cooccurrence of DS events and gamma oscillations at similar theta phases (Figs. 3D, 5B), we also compute PLV around randomly selected time points that are sampled from the theta phase distributions of the $D S_{L}$ and $D S_{M}$ events (gray profiles in Fig. 5D). The only significant departure 
from random was during $\mathrm{DS}_{\mathrm{M}}$, between the $\mathrm{SG}_{\mathrm{LPP}}$ and the $\mathrm{SG}_{S R}$ oscillations (Fig. $5 \mathrm{D}$, top right; paired $\left.t_{6}=4.04, p=0.006\right)$. The peak of this phase locking occurs 9 ms after the $D_{M}$ peak. Similarly, the $\mathrm{DS}_{\mathrm{M}}$-locked $\mathrm{SG}_{S R}$ oscillatory cycles lag the $\mathrm{SG}_{\mathrm{LPP}}$ oscillatory cycles by $6 \mathrm{~ms}$ (Fig. $\mathrm{S} 3 \mathrm{~A}, \mathrm{~B})$ pointing again to the $\mathrm{DG} \rightarrow \mathrm{CA} 1$ transmission time that was observed in Figs. $2 \mathrm{C}$ and 4A.

A
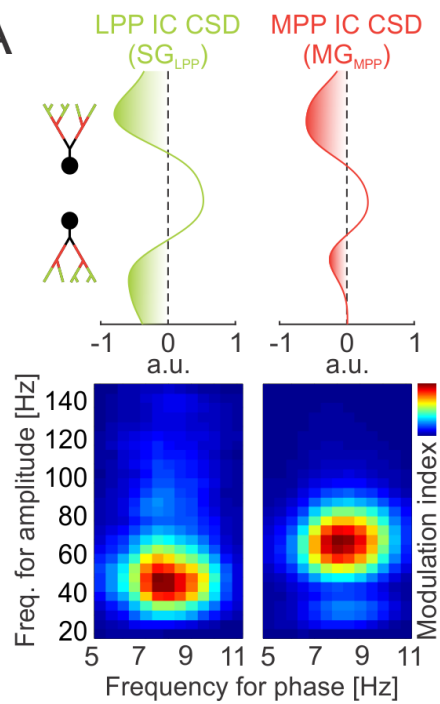

B

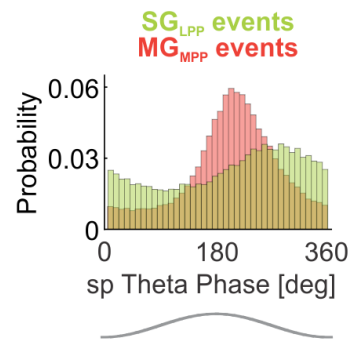

C
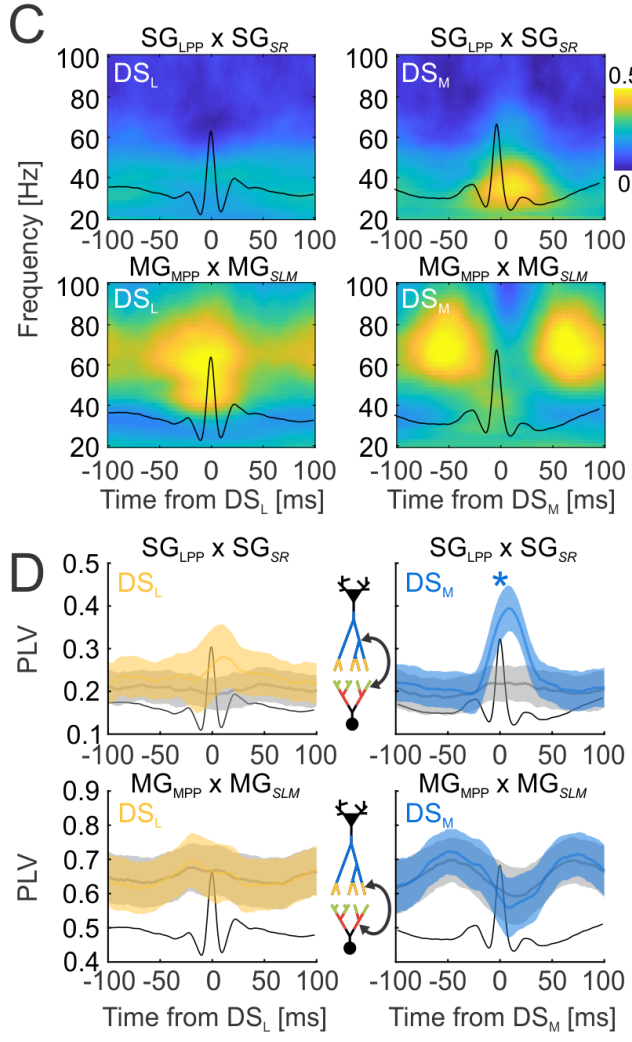
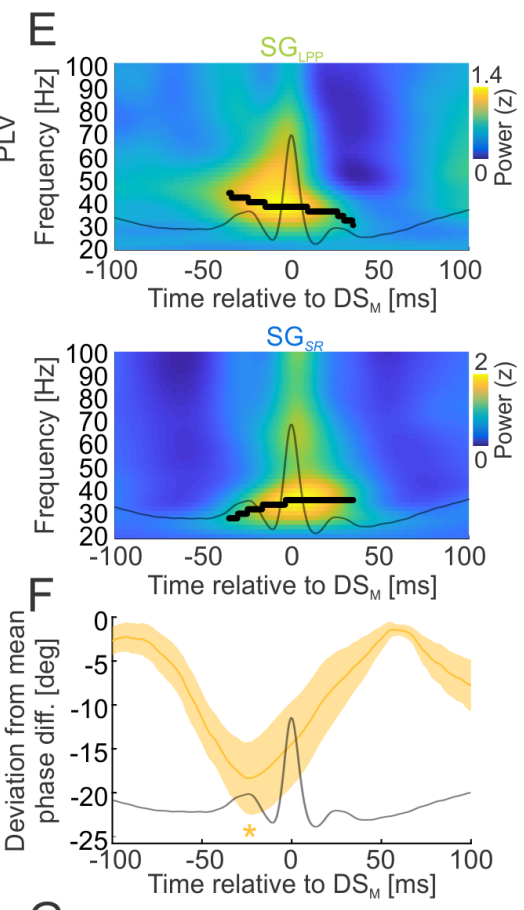

$G$ before $\mathrm{DS}_{\mathrm{M}}$ during $\mathrm{DS} \mathrm{S}_{\mathrm{M}}$

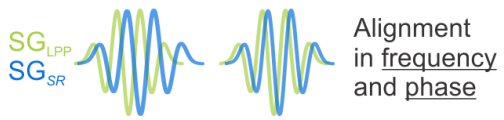

Figure 5. DS $\mathrm{M}_{\mathrm{M}}$ synchronizes the slow gamma oscillatory inputs from lateral perforant path to dentate gyrus and from CA3 to CA1 stratum radiatum. A) CSDs of ICA voltage loadings (top) of the LPP IC (SGLPP; green), and the MPP IC (MGMPp; red) in the DG. Comodulograms (bottom) between the phase of CA1 theta $(5-11 \mathrm{~Hz})$ and the amplitude of both IC components across $20-150 \mathrm{~Hz}$. B) Theta phase distribution of $\mathrm{SG}_{\mathrm{LPP}}$ (green) and $\mathrm{MG}_{\mathrm{MPP}}$ (red) oscillatory events. C) Example of phase locking value (PLV) between DG and CA1 slow gammas (SG LPP $_{X}$ $\mathrm{SG}_{S R}$; top) and between $\mathrm{DG}$ and $\mathrm{CA} 1$ mid-frequency gammas ( $\mathrm{MG}_{\mathrm{MPP}} \times \mathrm{MG}_{S L M}$; bottom) time- 
locked to $D S_{L}$ (left) and DS ${ }_{M}$ (right). D) Group PLV measures averaged across slow gamma (25$45 \mathrm{~Hz}$ for $\mathrm{SG}_{\mathrm{LPP}}$ and $\mathrm{SG}_{S R}$ ) and mid-frequency gamma (45-85 Hz for MG $\mathrm{LPP}_{\text {and }} \mathrm{MG}_{S L M}$ ). Gray: PLV profiles of random samples from the corresponding $D S_{L}$ and $D S_{M}$ theta phase distributions. E) Average wavelet spectrogram of $S_{L P P}\left(\right.$ top) and $S_{S R}$ (bottom) around the time of $\mathrm{DS}_{\mathrm{M}}(\mathrm{T}=$ $0 \mathrm{~ms}$ ). Black dots indicate frequency of peak power at each time point $\pm 40 \mathrm{~ms}$. F) Group average of how much the instantaneous phase differences between $S_{L P P}$ and $S_{S R}$ differ from the mean phase difference. Averages \pm S.E.M. and average DS waveforms (black) are plotted. G) Schematic of frequency and phase alignment of $S G_{L P P}$ and $S G_{S R}$ during $D S_{M}$.

\section{$C A 1 S G_{S R}$ and DG SG $G_{L P P}$ are frequency- and phase-tuned during $D S_{M}$}

Given a fixed duration of the gamma-generating $\mathrm{GABA}_{\mathrm{A}}$ receptor response, the frequency of a gamma oscillation can be adjusted by changing the level of network excitation, such that greater excitation produces faster oscillations because GABA inhibition can be overcome sooner

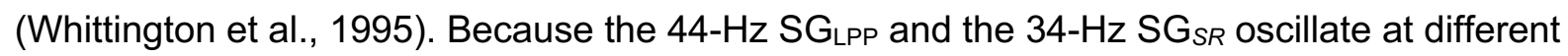
frequencies (Figs. 3C, 5A), but phase lock during $D S_{M}$ (Fig. 5D), the gamma-generating mechanism predicts input-driven changes in both the frequency and phase relationships for the phase alignment during $D S_{M}$. We analyze the frequency relationships of $S G_{L P P}$ and $S_{S R}$ during $D S_{M}$ to test the predictions, During $D S_{M}$, the frequency of $S G_{L P P}$ decreases from $43 \mathrm{~Hz}$ to $36 \mathrm{~Hz}$ at the peak of $D S_{M}$, whereas the frequency of $S G_{S R}$ increases from $28 \mathrm{~Hz}$ to $36 \mathrm{~Hz}$ at the peak of $D S_{M}$, effectively aligning the frequencies of the DG and CA1 originating oscillations (Fig. 5E). Analysis of the phase relationships of $S G_{L P P}$ and $S G_{S R}$ during $D S_{M}(F i g .5 F)$ shows the maximum deviation from the mean phase difference occurs 25 ms before the $D S_{M}$ peak $\left(t_{6}=\right.$ $4.51, p=0.004)$, and the phase offset reverts to the mean phase difference by $60 \mathrm{~ms}$ after the $D S_{M}$ peak $\left(t_{6}=2.37, p=0.06\right)$. At the peak of $D S_{M}$, the phase difference is reduced by 
$14.5 \pm 12.8^{\circ}$ (from 11 to $9 \mathrm{~ms}$ ), similar to the $\mathrm{DG} \rightarrow \mathrm{CA} 1$ transmission time observed in Figs. $2 \mathrm{C}$, 4A, 5D and S3A.

$D S_{M}$ increases DG, CA3 and CA1 discharge rates and cofiring

The hypothesis that $D S_{M}$ has a causal role in promoting $S_{\text {dom }}$ (Figs. 3, 4), and synchronizing slow gamma oscillations at the LPP terminals in DG and CA3 terminals in CA1 (Fig. 5), predicts that $\mathrm{DS}_{\mathrm{M}}$ organizes $\mathrm{DG}, \mathrm{CA} 3$, and $\mathrm{CA} 1$ discharge. Objectively classified, presumptive principal cells $(E)$ and narrow waveform interneurons $(\mathrm{In})$ were localized and studied to test the prediction (Fig. 6A, B; Star Methods). We compute the firing rates of presumptive granule cells (GC, $n=$ 141), mossy cells (MC, $n=140)$, CA3 $(n=104)$ and CA1 $(n=145)$ principal cells as well as narrow waveform interneurons detected in their proximity $(n=435)$ during 10 ms windows shifted relative to $D S_{L}$ and $D S_{M}$ events (Fig. $6 C$ ). These are compared with the firing rates at random times. DS events contaminated by SWR events were excluded to minimize potential SWR bias (Fig. 3G). During DS $\mathrm{L}$ the discharge of GC decreases by $13 \%\left(t_{140}=2.92, p=0.004\right)$. Similarly, the discharge of MC decreases by $19 \%\left(t_{139}=3.54, p=0.0005\right)$. CA3 and CA1 principal cells did not change firing rates (Fig. $6 C$; CA3: $t_{103}=1.36, p=0.18 ; C A 1: t_{144}=1.49, p$ $=0.14)$. In contrast, during $\mathrm{DS}_{\mathrm{M}}, \mathrm{GC}$ rates increase by $106 \%, \mathrm{MC}$ rates increase by $117 \%$, and CA3 rates increase by $47 \%$, whereas CA1 principal cell rates do not significantly increase as observed during $S_{\text {dom }}$ (Fig. $6 C ; G C: t_{140}=5.82, p=10^{-8} ; M C: t_{139}=6.15, p=10^{-9} ; C A 3: t_{103}=$ 3.02, $\left.p=0.003 ; C_{1} 1: t_{144}=1.65, p=0.1\right)$. During $D S_{L}$, the discharge of $G C$-associated $(n=96)$ and MC-associated $(n=89)$ narrow-waveform interneurons reduces by $10 \%$ and $8 \%$, respectively (Fig. $6 C ; G C$ In: $t_{95}=2.65, p=0.009 ; M C \ln : t_{88}=2.00, p=0.05$ ) while discharge of CA3-associated $(n=102)$ and CA1-associated $(n=148)$ narrow-waveform interneurons increases by $16 \%$ and $9 \%$, respectively (Fig. 6 C; CA3 In: $t_{101}=3.72, p=0.0003 ;$ CA1 In: $t_{147}=$ 
$2.40, p=0.017)$. In contrast, during $\mathrm{DS}_{\mathrm{M}}$, firing rates of $\mathrm{GC}-, \mathrm{MC}-, \mathrm{CA} 3-$ and CA1-associated interneurons increase by $263 \%, 58 \%, 71 \%$ and $25 \%$ respectively (Fig. 6 C; GC In: t95 $_{9}=9.51, p=$ 10-15; MC In: $\left.\mathrm{t}_{88}=3.41, \mathrm{p}=0.0009 ; \mathrm{CA} 3 \mathrm{In}: \mathrm{t}_{101}=6.28, \mathrm{p}=10^{-9} ; \mathrm{CA} 1 \mathrm{In}: \mathrm{t}_{147}=4.39, \mathrm{p}=10^{-5}\right)$.

These findings suggest that $D S_{\llcorner}$events result in net inactivation of both excitatory and inhibitory cells in DG and weak activation of interneurons in CA3 and CA1, without changing the firing rates of $\mathrm{CA} 3$ and $\mathrm{CA} 1$ principal cells, whereas $\mathrm{DS}_{\mathrm{M}}$ events result in strong activation of both excitatory and inhibitory cells along the $D G \rightarrow C A 3 \rightarrow C A 1$ trisynaptic pathway, with the primary effect in $\mathrm{CA} 1$ being to activate presumptive interneurons. The $\mathrm{DS}_{\mathrm{M}}$-associated increase of both excitatory and inhibitory cells establishes conditions for enhanced temporal control of principal cell discharge through excitation-inhibition coordination, and enhanced opportunities for cofiring that can enhance neural transmission across the $\mathrm{DG} \rightarrow \mathrm{CA} 3 \rightarrow \mathrm{CA} 1$ trisynaptic pathway (Ashhad and Feldman, 2020; Renart et al., 2010).

The hypothesis that $\mathrm{DS}_{\mathrm{M}}$ promotes $\mathrm{SG}_{\mathrm{dom}}$ by increasing neural control via $\mathrm{CA}$, predicts increased excitatory-inhibitory co-firing during DS $_{M}$ (Ashhad and Feldman, 2020; Renart et al., 2010), as does a recent finding of increased cofiring between excitatory and inhibitory dentate cell pairs during moments of active and successful discriminative memory recall (van Dijk and Fenton, 2018). We analyze the cofiring of pairs of principal cells (E) and narrow-waveform interneurons (I) within \pm 3 ms of $D S_{L}, D_{M}$ and random events (Fig. 6D; Table S1); DS events contaminated by SWR events were excluded. During $D S_{M}$, cofiring amongst the $G C$ and associated interneuron populations increases relative to chance (Fig. 6D, left; $649 \pm 734 \%$, $t_{464}$ $\left.=11.23, p=10^{-26}\right)$, whereas the cofiring decreases during $D S_{L}\left(65 \pm 108 \%, t_{464}=4.89, p=10^{-6}\right)$. Principal cell and interneuron cofiring also increases during DS $\mathrm{S}_{\mathrm{M}}$ within $\mathrm{CA} 3\left(232 \pm 299 \%, \mathrm{t}_{518}=\right.$ $\left.7.18, p=10^{-12}\right)$ but does not change during $D S_{L}\left(88 \pm 87 \% ; t_{518}=2.26, p=0.02\right)$. Increased cofiring between principal cells and interneurons is also observed within CA1 during DS $(132 \pm$ $\left.137 \% ; t_{361}=5.46, p=10^{-7}\right)$ indicating potentially increased inhibitory control of principal cell 
spiking during $D S_{M}$ but not during $D S_{L}\left(105 \pm 131 \% ; t_{361}=2.83, p=n . s\right.$. after Bonferroni correction). Cofiring also increased during $\mathrm{DS}_{\mathrm{M}}$ but not $\mathrm{DS} \mathrm{S}_{\mathrm{L}}$, between $\mathrm{MC}$ - and $\mathrm{GC}$-associated interneurons $\left(623 \pm 676 \%, \mathrm{t}_{121}=8.90, \mathrm{p}=10^{-15}\right)$ and between CA3- and CA1-associated interneurons $\left(180 \pm 214 \%, \mathrm{t}_{196}=5.53, \mathrm{p}=10^{-8}\right)$.

These increases in the propensity for cofiring during $\mathrm{DS}_{M}$ imply that local neurotransmission between excitatory and inhibitory cells is enhanced between synaptically-coupled cell pairs during $\mathrm{DS}_{\mathrm{M}}$. Enhanced spike-transmission strength estimated from cell pair spike time crosscorrelograms has been used to identify monosynaptically (excitatory) coupled cell pairs (Fig. 6E; English et al., 2017; Stark and Abeles, 2009). Summary of the types of cell-class pairs identified by enhanced short-latency spike-transmission strength highlights a greater likelihood of detecting intra-regional coupling, including via common input, and electrical synapses (review Traub et al., 2018; Fig. 6F), as may be the case for interneuron-interneuron cell pairs that exhibit zero-lag coupling. The average cross-correlograms confirm that during $\mathrm{DS}_{\mathrm{M}}$, cofiring is enhanced between excitatory - inhibitory cell pairs that are likely to be monosynaptically connected and possibly involved in rhythmogenesis (Figs. 3E, F; 4A) in DG, CA3 and CA1 (5 ms window; paired t test calculated at maximum cofiring value; GC/E x GC/I: $D S_{M}: t_{3}=3.41, p=$ $0.04 ; D_{L}: t_{3}=0.71, p=0.53 ; C A 3 / E x C A 3 / I: D S_{M}: t_{50}=4.62, p=10^{-5} ; D_{L}: t_{50}=2.96, p=0.004$; $\left.C A 1 / E \times C A 1 / I: D S_{M}: t_{29}=4.05, p=0.0003 ; D S_{L}: t_{29}=1.43, p=0.16\right)$. Furthermore, cofiring is enhanced during $D S_{M}$ but not $D S_{L}$ between pairs of granule cells $\left(G C / E \times G C / E ; D S_{M}: t_{4}=5.99\right.$, $\left.p=0.004 ; D S_{L}: t_{4}=1.11, p=0.32\right)$, pairs of CA3 interneurons $\left(C A 3 / I \times C A 3 / I ; D S_{M}: t_{13}=4.49, p\right.$ $\left.=0.0006 ; \mathrm{DS}_{\mathrm{L}}: \mathrm{t}_{13}=0.37, \mathrm{p}=0.72\right)$ and pairs of CA1 interneurons $\left(\mathrm{CA} 1 / \mathrm{I} \times \mathrm{CA} 1 / \mathrm{I} ; \mathrm{DS} \mathrm{S}_{\mathrm{M}}: \mathrm{t}_{9}=3.68\right.$, $\left.p=0.005 ; D S_{L}: t_{9}=1.61, p=0.14\right)$. Taken together, $D S_{M}$ selectively activates local excitationinhibition network discharge in both DG and CA3, which control neuron cofiring between the DG and CA3 networks, likely to promote $\mathrm{SG}_{\mathrm{dom}}$ and increased excitation-inhibition discharge in CA1. 

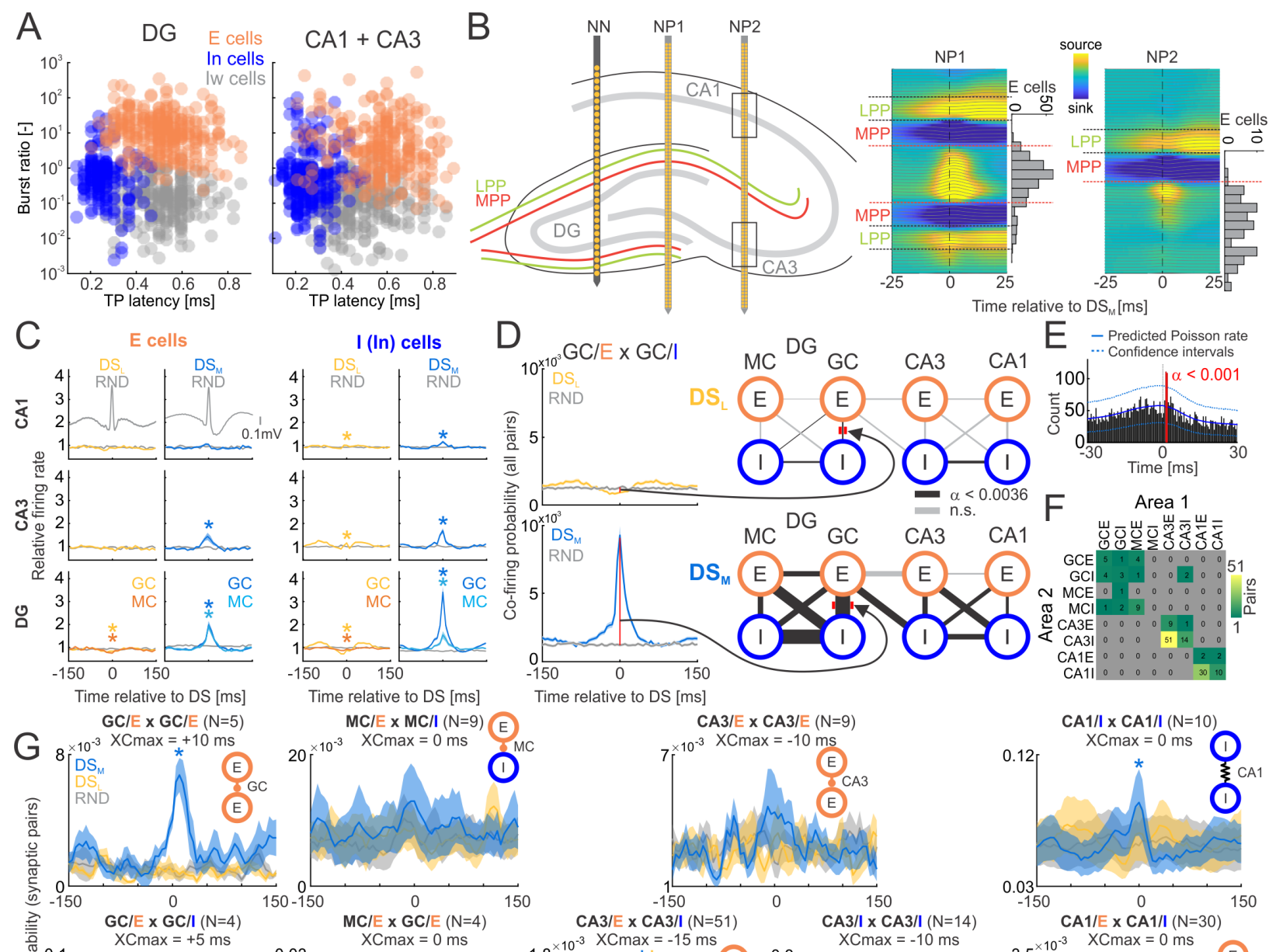

CA3 E $\quad$ CA1 $\begin{gathered}- \text { Predicted Poisson rate } \\ \cdots \text { Confidence intervals }\end{gathered}$

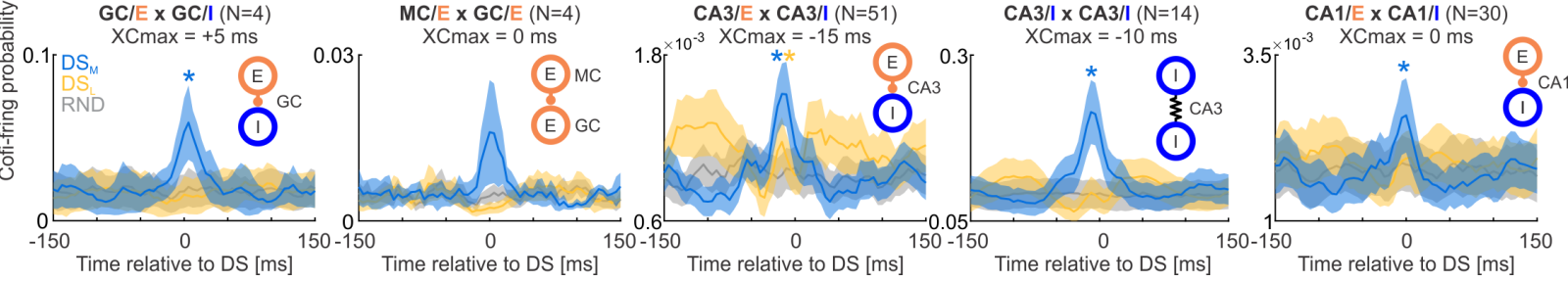

Figure 6. $D S_{M}$ increases action potential discharge and cofiring in DG, CA3, and CA1

networks. A) Unitary action potentials were classified as being from excitatory cells (E), narrowwaveform interneurons (In) and wide-waveform interneurons (Iw) using the K-means algorithm on the DG-localized (left) and separately, the CA3- and CA1-localized datasets (right). B) Schematic mouse hippocampus (left) with medial placement of Neuronexus linear electrode array (NN) for detection of DS events and two example lateral placements of Neuropixels probes, NP1 proximal to DG, NP2 proximal to CA3. Distinctive DS $\mathrm{M}_{\mathrm{M}}$-triggered average CSDs distinguishes DG and CA3 localization. Rectangles along NP2 show CA1 and CA3 unit 
localization (Fig. S5A). Corresponding depth distributions of putative excitatory cells are shown on the right of CSDs. Dotted lines: DG borders of granule cell (red) and outer molecular (black) layers. C) Normalized firing rates of CA1 (top), CA3 (middle), and DG (bottom) units during DS $\mathrm{L}_{\mathrm{L}}$ (left) and $D S_{M}$ (right) and random (gray) events. DS contaminated by SWR events were excluded. DS averages in gray. D) Representative cofiring probability of pairs of GC principal cells (GC/E) and proximal narrow waveform interneurons (GC/l) around $D S_{\llcorner}$(left, top, yellow) and $\mathrm{DS}_{\mathrm{M}}$ (left, bottom, blue) and random (gray) events. Ratio of cofiring probability during DS events and random times is represented as line thickness (right) in a DG $\rightarrow C A 3 \rightarrow C A 1$ network schematic; black connections significantly differ from random times, while grey connections do not after Bonferroni corrections (Table S1). E) Identification of a putative monosynaptic connection using enhanced spike-transmission strength in spike-time cross-correlogram. Solid blue line is expected cross-correlogram from Poisson model, dotted blue lines indicate confidence intervals, red bins mark significant deviations from the model. F) Summary matrix of counts of all identified monosynaptic pairs. G) Cofiring probability during $D S_{L}$ (yellow), $D S_{M}$ (blue) and random times (gray) in identified pairs with monosynaptic spike-transmission statistics. Title of each subplot shows time of maximum cross-correlation relative to DS, when statistics were computed. Stars mark significant deviations from random times. Averages \pm S.E.M. are plotted.

Finally, because $\mathrm{DS}_{\mathrm{M}}$ promotes synchronization of $\mathrm{SG}_{S R}$ and $\mathrm{SG}_{\mathrm{LPP}}$ in the slow gamma frequency range (Figs. 5C-F), neuronal discharge (Fig. 6C) and cofiring (Figs. 6D, G) within the DG-CA3-CA1 networks, it predicts that the $\mathrm{DS}_{\mathrm{M}}$-enhanced $\mathrm{SG}_{S R}$ gamma rhythm orchestrates the discharge through spike-field coupling that can maximize the efficiency of information transfer from DG to CA1. To evaluate this hypothesis, we examine the SG ${ }_{S R}$ and SG $\mathrm{LPP}_{\text {spike- }}$ field coupling during DS events (Fig. 7). The spiking of dentate granule cells, CA3 and CA1 
principal "E" cells is more organized at the trough of $\mathrm{SG}_{S R}$ oscillations in CA1 during DS compared to $D S_{L}$ (Figs. 7A-C; Kuiper test comparing the $\mathrm{DS}_{\mathrm{L}}$ - and $\mathrm{DS}_{\mathrm{M}}$-associated discharge probability distributions across $S_{S R}$ phase at time of the DS peak; GC/E: $k=1652, p=0.001$; CA3/E: $k=465, p=0.02 ; C A 1 / E: k=836, p=0.01)$. In contrast, at the time of $D S_{M}, S_{L P P}$ oscillations organize the local spiking of dentate GCs but not CA3 and CA1 principal cells when

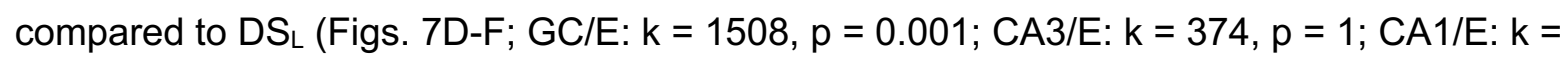
$516, p=1$ ). Similar relationships were observed for interneurons recorded in the vicinity of DG granule cells, CA3 and CA1 interneurons (Fig. S6). Taken together, these findings indicate that $D_{M}$ synchronizes discharge across the DG-CA3-CA1 trisynaptic circuit to $S_{S R}$, which enhances DG-CA1 transmission and promotes $\mathrm{SG}_{\mathrm{dom}}$.
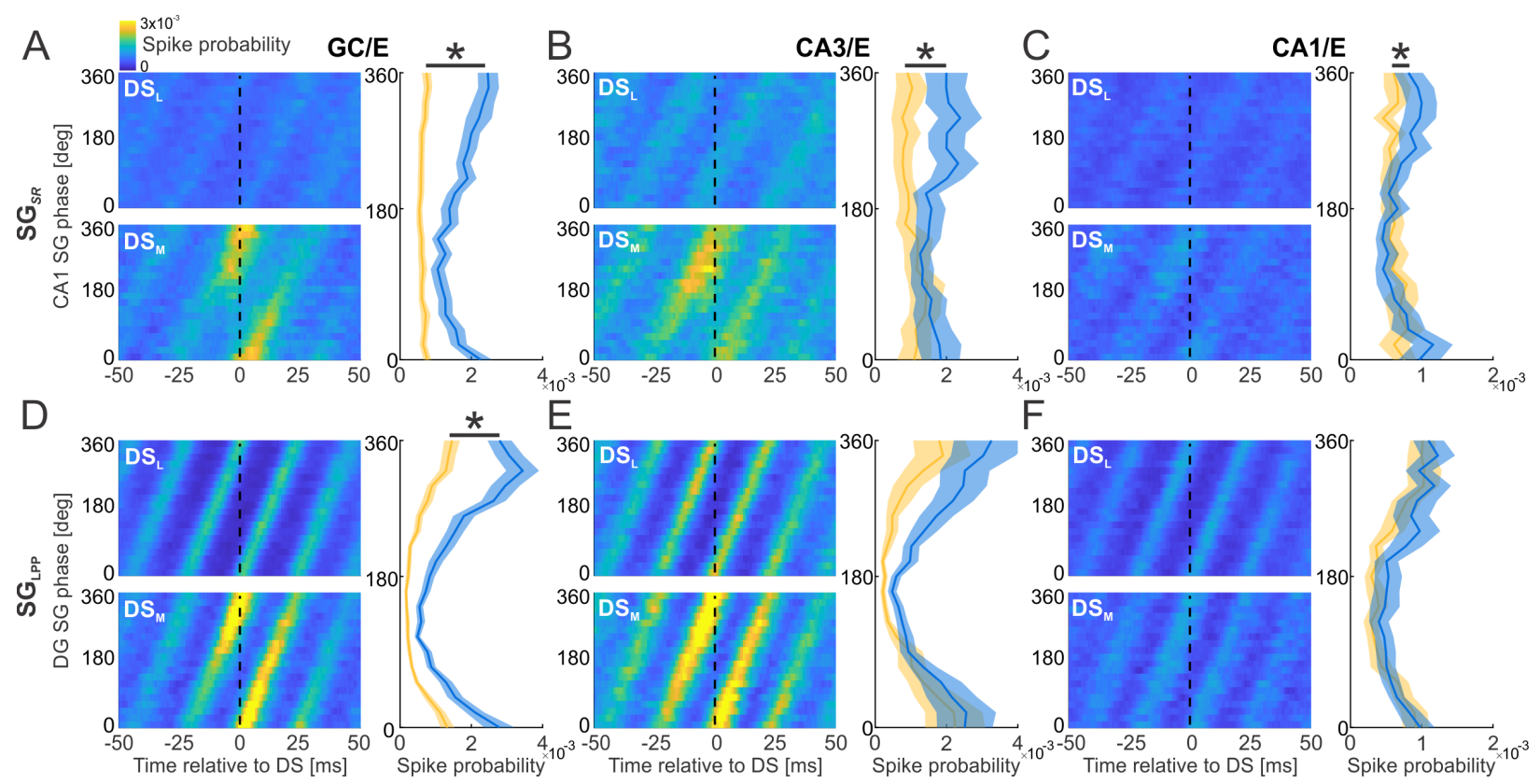

Figure 7. $D S_{M}$ phase synchronizes discharge of $G C, C A 3$ and $C A 1$ cells through $S_{S R} A$ )

Average discharge probability of a granule cell relative to $D S$ times ( $x$ axis; $D S_{L}$ top; $D S_{M}$ bottom) and $S_{S R}$ phase (y axis). Data averaged across cells for $D S_{L}$ (yellow) and $D S_{M}($ blue) at DS peak $(T=0)$ shown on right. Stars mark a significant difference between the $D S_{L}$ and $D S_{M}$ 
phase distributions. Same as (A), but for B) CA3 and C) CA1 principal cells. D) Same as (A), but for $\mathrm{SG}_{\mathrm{LPP}}$ gamma phase (y axis). Same as (D), but for E) CA3 and F) CA1 principal cells.

\section{Discussion}

\section{$D S_{M}$ control of information processing in Ammon's horn}

Our findings demonstrate entorhinal cortical control of information processing in hippocampus mediated by $D S_{M}$, the result of the synchronous activation of medial perforant path terminals at the middle molecular layer of dentate gyrus (Fig. 2; Bragin et al., 1995). The effects of DS ${ }_{M}$ on the $\mathrm{DG} \rightarrow \mathrm{CA} 3 \rightarrow \mathrm{CA} 1$ network are in dramatic and consistent contrast to the effects of $\mathrm{DS} \mathrm{S}_{\mathrm{L}}$ (Figs. 3-7), making it essential to distinguish them. Indeed, conclusions based on work that did not discriminate $D S_{L}$ from $D S_{M}$, have been hard to interpret (Bramham, 1998; Nokia et al., 2017). We have even observed that place avoidance training causes synaptic plasticity of the MPP synaptic response in the suprapyramidal molecular layers of DG with a corresponding change of $D S_{M}$ but not $D S_{L}$, corroborating the two pathways are distinctive and can be altered independently by experience (Chung et al., preprint).

The present findings point to a process of dynamic control of hippocampal information processing marked by transient physiological events across the trisynaptic pathway. During $\mathrm{SG}_{\mathrm{dom}} \mathrm{DG}, \mathrm{CA} 3$, and CA1 discharge is transiently elevated along with DG-CA3 cofiring (Fig. 6), and there is slow gamma frequency and phase synchronization between LPP inputs to DG and the stratum radiatum input from CA3 to CA1 (Figs. 5, 7), indicating involvement of the entire trisynaptic pathway, similar to SWR (Buzsaki et al., 2003; Sullivan et al., 2011). Indeed, during $\mathrm{DS}_{\mathrm{M}}$, SWR probability in a $20 \mathrm{~ms}$ window increases from $1.2 \%$ to $1.8 \%$ (Fig. 3G) and place cell discharge is non-local during SWR (Buzsaki, 2015; O'Neill et al., 2006; Papale et al., 2016; Sullivan et al., 2011) as well as during $S_{\text {dom }}$ (Fig. 1; Dvorak et al., 2018). 
The qualitative distinction between information signaled by LEC and MEC is important in this context. LEC transmits contextual information based on objects and egocentric information that constitutes the content of spatial experience (Knierim et al., 2014; Tsao et al., 2013; Wang et al., 2018), whereas MEC transmits allocentric spatial signals like direction, distance, borders, and speed (Hargreaves et al., 2005; Rowland et al., 2018; Sargolini et al., 2006; Ye et al., 2018). Remarkably, the MEC-originating $D S_{M}$ signal that promotes $S_{\text {dom }}$ and switches $C A 1$ to non-local positional memory processing is coincident with synchronization between CA3transmitted slow gamma inputs to CA1 and LEC-transmitted slow gamma inputs to DG, rather than from MEC (Figs. 5, 7). Within the "communication through coherence" hypothesis (Fries et al., 2007), the $L E C \rightarrow D G$ and $C A 3 \rightarrow C A 1$ inputs have a privileged opportunity for information transfer via synchronized slow gamma transmission, and so we speculate that perhaps while switching the hippocampal information processing mode, $\mathrm{DS}_{\mathrm{M}}$ loads Ammon's horn with information from the LEC-delivered egocentric contents of experience. In this way, during DS ${ }_{\mathrm{M}}$, the consequent activation of CA3 may be preferentially influenced by contextual and egocentric, ecphoric retrieval cues delivered by the LEC inputs (Kelemen and Fenton, 2013; Tulving et al., 1983). If these manifest as $S G_{d o m}$ because of the strong $D S_{M}$-associated activation of $C A 3$ (Figs. 6,7 ), the result is control of CA1 output that overrides the default control that is exerted by the mid-frequency gamma mediated ECIII input at s/m (Brun et al., 2002). These s/m inputs appear necessary for place cell firing (Brun et al., 2008), and they create permissive dendritic depolarization (Jarsky et al., 2005), but in principle can be shunted by the slow gammaassociated inputs (Keeley et al., 2017), and are possibly actively inhibited as a consequence of $\mathrm{DS}_{\mathrm{M}}(\mathrm{Fig} .4 \mathrm{~F})$, all of which promote $\mathrm{SG}_{\mathrm{dom}}(\mathrm{Fig} .3 \mathrm{H})$. As we have observed during $\mathrm{SG}_{\mathrm{dom}}, \mathrm{CA} 1$ discharge will signal non-local positions that during a memory task, correspond to recollected places (Dvorak et al., 2018), and we observed here a correspondingly reduced local discharge by place cells in their firing fields (Fig. 1), despite maintained CA1 firing (Fig. 6C). Indeed, the findings of a hippocampus-wide (Figs. 6, 7), $\mathrm{DS} \mathrm{S}_{\mathrm{M}}$-promoted $\mathrm{SG}_{\mathrm{dom}}$ change to a non-local mode 
of information processing identifies a source of the overdispersion that is characteristic of place cells in CA1, CA3, and DG (Fenton et al., 2010; Fenton and Muller, 1998; Hok et al., 2012; Jackson and Redish, 2007; van Dijk and Fenton, 2018), and also grid cells, although we cannot conclude the mechanism is the same (Nagele et al., 2020). The findings also offer an explanation for the possible utility of CA1 receiving two spatial inputs; the Schaffer collaterals provide place cell inputs that can be non-local and related to mental experience, whereas the temporoammonic pathway provides an input comprised of components of place (grid cell distances, directional cells, border cells, and speed cells) more tethered to local, physical experience.

\section{References}

Ashhad, S., and Feldman, J.L. (2020). Emergent Elements of Inspiratory Rhythmogenesis: Network Synchronization and Synchrony Propagation. Neuron 106, 482-497.e484.

Barth, A.M., Domonkos, A., Fernandez-Ruiz, A., Freund, T.F., and Varga, V. (2018). Hippocampal Network Dynamics during Rearing Episodes. Cell Rep 23, 1706-1715.

Bragin, A., Jando, G., Nadasdy, Z., van Landeghem, M., and Buzsaki, G. (1995). Dentate EEG spikes and associated interneuronal population bursts in the hippocampal hilar region of the rat. J Neurophysiol 73, 1691-1705.

Bramham, C.R. (1998). Phasic boosting of medial perforant path-evoked granule cell output time-locked to spontaneous dentate EEG spikes in awake rats. J Neurophysiol 79, 28252832.

Brun, V.H., Leutgeb, S., Wu, H.Q., Schwarcz, R., Witter, M.P., Moser, E.I., and Moser, M.B. (2008). Impaired Spatial Representation in CA1 after Lesion of Direct Input from Entorhinal Cortex. Neuron 57, 290-302. 
Brun, V.H., Otnass, M.K., Molden, S., Steffenach, H.A., Witter, M.P., Moser, M.B., and Moser, E.I. (2002). Place cells and place recognition maintained by direct entorhinalhippocampal circuitry. Science 296, 2243-2246.

Buzsaki, G. (2015). Hippocampal sharp wave-ripple: A cognitive biomarker for episodic memory and planning. Hippocampus 25, 1073-1188.

Buzsaki, G., Buhl, D.L., Harris, K.D., Csicsvari, J., Czeh, B., and Morozov, A. (2003). Hippocampal network patterns of activity in the mouse. Neuroscience 116, 201-211.

Chung, A., Garcia-Jou, C., Dvorak, D., Hussain, N., and Fenton, A. (preprint). Learning to learn persistently modifies a cortical-hippocampal excitatory-inhibitory subcircuit. bioRxiv, 817627.

Colgin, L.L. (2015). Do slow and fast gamma rhythms correspond to distinct functional states in the hippocampal network? Brain Res 1621, 309-315.

Csicsvari, J., Hirase, H., Czurko, A., Mamiya, A., and Buzsaki, G. (1999). Fast network oscillations in the hippocampal CA1 region of the behaving rat. J Neurosci 19, RC20. de Almeida, L., Idiart, M., and Lisman, J.E. (2009). A second function of gamma frequency oscillations: an E\%-max winner-take-all mechanism selects which cells fire. J Neurosci 29, 7497-7503.

Dvorak, D., and Fenton, A.A. (2014). Toward a proper estimation of phase-amplitude coupling in neural oscillations. J Neurosci Methods 225, 42-56.

Dvorak, D., Radwan, B., Sparks, F.T., Talbot, Z.N., and Fenton, A.A. (2018). Control of recollection by slow gamma dominating mid-frequency gamma in hippocampus CA1. PLoS Biol 16, e2003354.

English, D.F., McKenzie, S., Evans, T., Kim, K., Yoon, E., and Buzsaki, G. (2017). Pyramidal Cell-Interneuron Circuit Architecture and Dynamics in Hippocampal Networks. Neuron 96, 505-520 e507. 
Fenton, A.A., Lytton, W.W., Barry, J.M., Lenck-Santini, P.P., Zinyuk, L.E., Kubik, S., Bures, J., Poucet, B., Muller, R.U., and Olypher, A.V. (2010). Attention-like modulation of hippocampus place cell discharge. J Neurosci 30, 4613-4625.

Fenton, A.A., and Muller, R.U. (1998). Place cell discharge is extremely variable during individual passes of the rat through the firing field. Proc Natl Acad Sci U S A 95, 31823187.

Fernandez-Ruiz, A., and Herreras, O. (2013). Identifying the synaptic origin of ongoing neuronal oscillations through spatial discrimination of electric fields. Front Comput Neurosci 7, 5.

Fernandez-Ruiz, A., Munoz, S., Sancho, M., Makarova, J., Makarov, V.A., and Herreras, O. (2013). Cytoarchitectonic and dynamic origins of giant positive local field potentials in the dentate gyrus. J Neurosci 33, 15518-15532.

Fernandez-Ruiz, A., Oliva, A., Nagy, G.A., Maurer, A.P., Berenyi, A., and Buzsaki, G. (2017). Entorhinal-CA3 Dual-Input Control of Spike Timing in the Hippocampus by ThetaGamma Coupling. Neuron 93, 1213-1226 e1215.

Fries, P., Nikolic, D., and Singer, W. (2007). The gamma cycle. Trends Neurosci 30, 309-316.

Garner, A.R., Rowland, D.C., Hwang, S.Y., Baumgaertel, K., Roth, B.L., Kentros, C., and Mayford, M. (2012). Generation of a synthetic memory trace. Science 335, 1513-1516. Hargreaves, E.L., Rao, G., Lee, I., and Knierim, J.J. (2005). Major dissociation between medial and lateral entorhinal input to dorsal hippocampus. Science 308, 1792-1794.

Harris, K.D., Csicsvari, J., Hirase, H., Dragoi, G., and Buzsaki, G. (2003). Organization of cell assemblies in the hippocampus. Nature 424, 552-556.

Headley, D.B., Kanta, V., and Pare, D. (2017). Intra- and interregional cortical interactions related to sharp-wave ripples and dentate spikes. J Neurophysiol 117, 556-565.

Hebb, D.O. (1949). The organization of behavior, a neuropsychological theory (New York: Wiley). 
Hok, V., Chah, E., Reilly, R.B., and O'Mara, S.M. (2012). Hippocampal dynamics predict interindividual cognitive differences in rats. J Neurosci 32, 3540-3551.

Hyvarinen, A. (1999). Fast and robust fixed-point algorithms for independent component analysis. IEEE Trans Neural Netw 10, 626-634.

Jackson, J., and Redish, A.D. (2007). Network dynamics of hippocampal cell-assemblies resemble multiple spatial maps within single tasks. Hippocampus 17, 1209-1229.

Jarsky, T., Roxin, A., Kath, W.L., and Spruston, N. (2005). Conditional dendritic spike propagation following distal synaptic activation of hippocampal CA1 pyramidal neurons. Nat Neurosci 8, 1667-1676.

Jia, X., Siegle, J.H., Bennett, C., Gale, S.D., Denman, D.J., Koch, C., and Olsen, S.R. (2019). High-density extracellular probes reveal dendritic backpropagation and facilitate neuron classification. J Neurophysiol 121, 1831-1847.

Johnson, A., and Redish, A.D. (2007). Neural ensembles in CA3 transiently encode paths forward of the animal at a decision point. J Neurosci 27, 12176-12189.

Jun, J.J., Steinmetz, N.A., Siegle, J.H., Denman, D.J., Bauza, M., Barbarits, B., Lee, A.K., Anastassiou, C.A., Andrei, A., Aydin, C., et al. (2017). Fully integrated silicon probes for high-density recording of neural activity. Nature 551, 232-236.

Kanter, B.R., Lykken, C.M., Avesar, D., Weible, A., Dickinson, J., Dunn, B., Borgesius, N.Z., Roudi, Y., and Kentros, C.G. (2017). A Novel Mechanism for the Grid-to-Place Cell Transformation Revealed by Transgenic Depolarization of Medial Entorhinal Cortex Layer II. Neuron 93, 1480-1492 e1486.

Kay, K., Chung, J.E., Sosa, M., Schor, J.S., Karlsson, M.P., Larkin, M.C., Liu, D.F., and Frank, L.M. (2020). Constant Sub-second Cycling between Representations of Possible Futures in the Hippocampus. Cell.

Keeley, S., Fenton, A.A., and Rinzel, J. (2017). Modeling fast and slow gamma oscillations with interneurons of different subtype. J Neurophysiol 117, 950-965. 
Kelemen, E., and Fenton, A.A. (2010). Dynamic grouping of hippocampal neural activity during cognitive control of two spatial frames. PLoS Biol 8, e1000403.

Kelemen, E., and Fenton, A.A. (2013). Key features of human episodic recollection in the crossepisode retrieval of rat hippocampus representations of space. PLoS Biol 11, e1001607.

Kelemen, E., and Fenton, A.A. (2016). Coordinating different representations in the hippocampus. Neurobiol Learn Mem 129, 50-59.

Knierim, J.J., Neunuebel, J.P., and Deshmukh, S.S. (2014). Functional correlates of the lateral and medial entorhinal cortex: objects, path integration and local-global reference frames. Philos Trans R Soc Lond B Biol Sci 369, 20130369.

Lachaux, J.P., Rodriguez, E., Martinerie, J., and Varela, F.J. (1999). Measuring phase synchrony in brain signals. Hum Brain Mapp 8, 194-208.

Lasztoczi, B., and Klausberger, T. (2014). Layer-Specific GABAergic Control of Distinct Gamma Oscillations in the CA1 Hippocampus. Neuron 81, 1126-1139.

Lasztoczi, B., and Klausberger, T. (2016). Hippocampal Place Cells Couple to Three Different Gamma Oscillations during Place Field Traversal. Neuron 91, 34-40.

Makarov, V.A., Makarova, J., and Herreras, O. (2010). Disentanglement of local field potential sources by independent component analysis. J Comput Neurosci 29, 445-457.

Miao, C., Cao, Q., Ito, H.T., Yamahachi, H., Witter, M.P., Moser, M.B., and Moser, E.I. (2015). Hippocampal Remapping after Partial Inactivation of the Medial Entorhinal Cortex. Neuron 88, 590-603.

Mizuseki, K., Royer, S., Diba, K., and Buzsaki, G. (2012). Activity dynamics and behavioral correlates of CA3 and CA1 hippocampal pyramidal neurons. Hippocampus 22, 1659 1680.

Nagele, J., Herz, A.V.M., and Stemmler, M.B. (2020). Untethered firing fields and intermittent silences: Why grid-cell discharge is so variable. Hippocampus n/a. 
Nokia, M.S., Gureviciene, I., Waselius, T., Tanila, H., and Penttonen, M. (2017). Hippocampal electrical stimulation disrupts associative learning when targeted at dentate spikes. J Physiol 595, 4961-4971.

O'Neill, J., Senior, T., and Csicsvari, J. (2006). Place-selective firing of CA1 pyramidal cells during sharp wave/ripple network patterns in exploratory behavior. Neuron 49, 143-155.

Olypher, A.V., Lansky, P., and Fenton, A.A. (2002a). On the location-specific positional and extra-positional information in the discharge of rat hippocampal cells. Biosystems 67 , $167-175$.

Olypher, A.V., Lansky, P., and Fenton, A.A. (2002b). Properties of the extra-positional signal in hippocampal place cell discharge derived from the overdispersion in location-specific firing. Neuroscience 111, 553-566.

Pachitariu, M., Steinmetz, N., Kadir, S., Carandini, M., and Harris, K.D. (2016). Kilosort: realtime spike-sorting for extracellular electrophysiology with hundreds of channels. bioRxiv 061481 (2016).

Papale, A.E., Zielinski, M.C., Frank, L.M., Jadhav, S.P., and Redish, A.D. (2016). Interplay between Hippocampal Sharp-Wave-Ripple Events and Vicarious Trial and Error Behaviors in Decision Making. Neuron 92, 975-982.

Pastalkova, E., Itskov, V., Amarasingham, A., and Buzsaki, G. (2008). Internally generated cell assembly sequences in the rat hippocampus. Science $321,1322-1327$.

Penttonen, M., Kamondi, A., Sik, A., Acsady, L., and Buzsaki, G. (1997). Feed-forward and feed-back activation of the dentate gyrus in vivo during dentate spikes and sharp wave bursts. Hippocampus 7, 437-450.

Pettersen, K.H., Devor, A., Ulbert, I., Dale, A.M., and Einevoll, G.T. (2006). Current-source density estimation based on inversion of electrostatic forward solution: Effects of finite extent of neuronal activity and conductivity discontinuities. Journal of Neuroscience Methods 154, 116-133. 
Renart, A., de la Rocha, J., Bartho, P., Hollender, L., Parga, N., Reyes, A., and Harris, K.D. (2010). The asynchronous state in cortical circuits. Science 327, 587-590.

Rolls, E.T., and Treves, A. (1998). Neural Networks and Brain Function (Oxford: Oxford University Press).

Rowland, D.C., Obenhaus, H.A., Skytoen, E.R., Zhang, Q., Kentros, C.G., Moser, E.I., and Moser, M.B. (2018). Functional properties of stellate cells in medial entorhinal cortex layer II. Elife 7.

Sargolini, F., Fyhn, M., Hafting, T., McNaughton, B.L., Witter, M.P., Moser, M.B., and Moser, E.I. (2006). Conjunctive representation of position, direction, and velocity in entorhinal cortex. Science 312, 758-762.

Schlesiger, M.I., Boublil, B.L., Hales, J.B., Leutgeb, J.K., and Leutgeb, S. (2018). Hippocampal Global Remapping Can Occur without Input from the Medial Entorhinal Cortex. Cell Rep 22, 3152-3159.

Schomburg, E.W., Anastassiou, C.A., Buzsaki, G., and Koch, C. (2012). The spiking component of oscillatory extracellular potentials in the rat hippocampus. J Neurosci 32, 1179811811.

Schomburg, E.W., Fernandez-Ruiz, A., Mizuseki, K., Berenyi, A., Anastassiou, C.A., Koch, C., and Buzsaki, G. (2014). Theta phase segregation of input-specific gamma patterns in entorhinal-hippocampal networks. Neuron 84, 470-485.

Senzai, Y., and Buzsaki, G. (2017). Physiological Properties and Behavioral Correlates of Hippocampal Granule Cells and Mossy Cells. Neuron 93, 691-704 e695.

Stark, E., and Abeles, M. (2009). Unbiased estimation of precise temporal correlations between spike trains. J Neurosci Methods 179, 90-100.

Sullivan, D., Csicsvari, J., Mizuseki, K., Montgomery, S., Diba, K., and Buzsaki, G. (2011). Relationships between hippocampal sharp waves, ripples, and fast gamma oscillation: influence of dentate and entorhinal cortical activity. J Neurosci 31, 8605-8616. 
Talbot, Z.N., Sparks, F.T., Dvorak, D., Curran, B.M., Alarcon, J.M., and Fenton, A.A. (2018). Normal CA1 Place Fields but Discoordinated Network Discharge in a Fmr1-Null Mouse Model of Fragile X Syndrome. Neuron.

Tort, A.B., Komorowski, R., Eichenbaum, H., and Kopell, N. (2010). Measuring phase-amplitude coupling between neuronal oscillations of different frequencies. J Neurophysiol 104, 1195-1210.

Traub, R.D., Whittington, M.A., Gutiérrez, R., and Draguhn, A. (2018). Electrical coupling between hippocampal neurons: contrasting roles of principal cell gap junctions and interneuron gap junctions. Cell and Tissue Research 373, 671-691.

Tsao, A., Moser, M.B., and Moser, E.I. (2013). Traces of experience in the lateral entorhinal cortex. Curr Biol 23, 399-405.

Tulving, E., Le Voi, M.E., Routh, D.A., and Loftus, E. (1983). Ecphoric processes in episodic memory. Philos Trans R Soc Lond B Biol Sci 302, 361-371.

van Dijk, M.T., and Fenton, A.A. (2018). On How the Dentate Gyrus Contributes to Memory Discrimination. Neuron 98, 832-845.

Vinck, M., Oostenveld, R., van Wingerden, M., Battaglia, F., and Pennartz, C.M. (2011). An improved index of phase-synchronization for electrophysiological data in the presence of volume-conduction, noise and sample-size bias. Neuroimage 55, 1548-1565.

Wang, C., Chen, X., Lee, H., Deshmukh, S.S., Yoganarasimha, D., Savelli, F., and Knierim, J.J. (2018). Egocentric coding of external items in the lateral entorhinal cortex. Science 362, 945-949.

Whittington, M.A., Traub, R.D., and Jefferys, J.G. (1995). Synchronized oscillations in interneuron networks driven by metabotropic glutamate receptor activation. Nature 373, 612-615.

Wu, C.T., Haggerty, D., Kemere, C., and Ji, D. (2017). Hippocampal awake replay in fear memory retrieval. Nat Neurosci 20, 571-580. 
Ye, J., Witter, M.P., Moser, M.B., and Moser, E.I. (2018). Entorhinal fast-spiking speed cells project to the hippocampus. Proc Natl Acad Sci U S A 115, E1627-E1636.

Zhang, K., Ginzburg, I., McNaughton, B.L., and Sejnowski, T.J. (1998). Interpreting neuronal population activity by reconstruction: unified framework with application to hippocampal place cells. J Neurophysiol 79, 1017-1044. 


\section{STAR Methods}

\section{Subjects}

A total of 14 wild-type mice with a mixed C57BL/6J background were used for the study. The mice were 3 - 6 months old during surgery. Nine mice were implanted with linear silicon arrays. Three mice were implanted with a metal head plate for head-fixed recording using linear silicon arrays and Neuropixels probes (Jun et al., 2017). Two mice from a previously published dataset were implanted with tetrodes (Dvorak et al., 2018).

\section{Surgery}

LFP recordings were collected using 32-channel (8 mice) and 16-channel (1 mouse) linear silicon array electrodes (Neuronexus, Ann Arbor, MI) with $50 \mu \mathrm{m}$ spacing and $703 \mathrm{um}^{2}$ electrode area. The 32-channel electrodes spanned both CA1 and DG locations, and the 16-channel electrode spanned only DG locations. The electrodes were implanted stereotaxically under isoflurane anesthesia $(2 \%, 1 \mathrm{~L} / \mathrm{min})$. The tip was aimed at $-1.85 \mathrm{AP}, \pm 1.20 \mathrm{ML},-2.3 \mathrm{DV}$ relative to bregma. The electrodes spanned the dorso-ventral axis of the dorsal hippocampus.

Reference electrodes were aimed at the cerebellar white matter. The electrode assemblies were anchored to the skull using 3-4 bone screws with dental cement (Grip Cement, Dentsply, Milford DE). One anterior screw was used as a ground. A four-wire stimulating electrode bundle was made by twisting together four 75- $\mu$ m diameter nichrome wires (California Fine Wire, Grover Beach, CA). The bundle was cut at an angle so as to span $0.5 \mathrm{~mm}$. During surgery, the stimulating bundle was placed in the ipsilateral perforant path $+0.5 \mathrm{AP}, \pm 4.1 \mathrm{ML}, 1.0-1.6 \mathrm{DV}$ from lambda. Evoked response waveforms were carefully checked with different pair combinations of stimulation electrode channels. In the mice that were used for head-fixed recordings, a titanium head plate was attached to the skull using dental cement and the exposed skull was covered with KwikSil, a low toxicity adhesive (World Precision Instruments, 
Sarasota, FL) and protected by attaching a plastic cup. All mice were allowed at least 1 week to recover. In mice that were used for head-fixed recordings, a secondary surgery was performed immediately before the experiment. The plastic cup and KwikSil were removed and a craniotomy was made at $1.85 \mathrm{AP}, \pm 1.20 \mathrm{ML}$ relative to bregma to enable electrode placement. Between consecutive days of recordings, a KwikSil protective cup assembly was reattached to prevent infection.

\section{Behavioral tasks}

Nine mice with implanted linear silicon probe arrays and 2 mice implanted with tetrodes were trained in the active place avoidance task. Each day consisted of a 30 min rest session in the home-cage, which was placed in the recording chamber, followed by a 30-min place avoidance session. After habituation (shock off), a total of 3 training sessions (shock on) were administered to all animals, one session each day. A retention session with the shock on followed 1 week after. Electrophysiology data from 9 mice implanted with linear silicon probe arrays and recorded during rest were used for Figs. 2, 3A-G and 5. Electrophysiology data from the same group recorded during place avoidance were used for Figs. 1A, B, 3H and 4. Electrophysiology data from the 2 mice implanted with tetrodes were used for Figs. 1C, D. Two mice were recorded in a custom head-fixed setup using both Neuropixels and Neuronexus linear silicon probe arrays during 59 sessions (average length $15.7 \pm 3.9 \mathrm{~min}$ ) spread over multiple days. Mice were encouraged to walk using a custom water delivery system. Electrophysiology data recorded in head-fixed mice were used for Figs. 6, 7.

\section{Electrophysiology recording}

An amplifier board with 32 unipolar inputs and 3-axis accelerometer (RHD2132, Intan Technologies, Los Angeles, CA) was connected directly to the Neuronexus probe for signal amplification and digitization. A lightweight, counter-balanced cable (Intan Technologies, Los 
Angeles, CA) was used to power the amplifier board and the infrared LED used for tracking as well as to transmit digital data to the computer using a custom recording system connected to the USB port of a PC. The cable was connected through a lightweight commutator to enable free movement of the animal. The signal from each electrode was low-pass filtered $(500 \mathrm{~Hz})$ and digitized at $2 \mathrm{kHz}$. Evoked responses were obtained using a constant current stimulus isolation unit (WPI, Sarasota, FL; model: A365RC) that was used to deliver individual unipolar $100 \mu$ s stimulus pulses across the electrode pair. Evoked responses were low-pass filtered at 4 $\mathrm{kHz}$ and sampled at $8.12 \mathrm{kHz}$. In head-fixed recordings, the signal from a Neuropixels probe was filtered between $0.5 \mathrm{~Hz}$ and $1 \mathrm{kHz}$ and sampled at $2.5 \mathrm{kHz}$ for LFP recordings and filtered between $300 \mathrm{~Hz}$ and $10 \mathrm{kHz}$ and sampled at $30 \mathrm{kHz}$ for single unit recording. Both electrophysiology systems were synchronized using square TTL pulses generated by the Neuropixels system that was recorded by both systems. The animals were recorded during a 30-minute session in their home-cage during the first exposure to the experimental room. The mouse's movements during recordings were monitored continuously using a video tracking system (Tracker, Bio-Signal Group, Acton, MA) that was synchronized to the electrophysiology data using the video frame pulses generated by the camera.

\section{Data Analysis}

\section{LFP and electrode localization}

LFPs were localized by visual LFP inspection of sharp-wave ripples in CA1 stratum pyramidale and dentate spikes in the hilus of the dentate gyrus (Fig. S1E). Electrode locations were verified histologically at the end of recordings (Fig. S1F, G). In the mouse implanted with the 16-ch electrode array, only dentate LFPs were recorded because of the limited spatial span of the electrode. 
A published algorithm was used to extract oscillatory events from LFP or independent components obtained using ICA (Dvorak and Fenton, 2014). The LFP is transformed into a time-frequency power representation by convolving the LFP/IC signal with a group of complex Morlet wavelets and z-score normalizing each band-specific signal. Oscillatory events are detected as local peaks in the normalized 2-D time-frequency space. Detection of oscillation rates and $S_{\text {dom }}$ events was described previously (Dvorak et al., 2018). Oscillation rates (Fig. $1 \mathrm{~A}$, lower) are computed as the number of detected events in a representative frequency range (30-50 for CA1 slow gamma, 70-90 Hz for CA1 mid-frequency gamma) in a 1-s window advanced by $0.25 \mathrm{~s}$ and smoothed using $2.5 \mathrm{~s}$ moving average. SG/MG ratio (Fig. $1 \mathrm{~A}$, lower) is computed as a ratio of CA1 slow gamma oscillation rate and CA1 mid-frequency gamma oscillation rate. $\mathrm{SG}_{\text {dom }}$ events, are defined as local peaks in SG/MG ratio with prominence exceeding 1 and SG/MG ratio > 1 (corresponding to $S G>M G$ ).

\section{Detection and classification of dentate spikes}

The LFP channel with the largest visually identified amplitude of dentate spike was band-pass filtered $5-100 \mathrm{~Hz}$ and the amplitude was z-score normalized. Next, all local peaks in the bandpass signal were detected, and several features were extracted, including the amplitude difference between the DS maxima and the preceding as well as following minima, and also the spike width that was measured at the level of either the preceding or following minima, whichever was closer to the maxima. The spike amplitude distributions were further normalized by z-score normalization of the log-transformed amplitudes. Putative dentate spikes were selected if their prominence (difference between amplitude of the DS maxima and the smaller of either its preceding or the following minima) $>0.75$ and when the width of the event was between 5 and $25 \mathrm{~ms}$. The optimal values were selected based on analysis of the feature histograms. 
Dentate spikes were classified as $D S_{L}$ and $D S_{M}$ based on their CSD profiles (Bragin et al., 1995). CSDs were calculated using the CSDplotter Matlab toolbox (Pettersen et al., 2006) at the peak of a putative DS event. Independently for each recording, the CSD for each putative DS event was analyzed for local minima, corresponding to CSD sinks (Fig. 2B). The histogram of detected local minima of all putative DS events was plotted and the local maxima that represented the highest probability of current sinks were manually identified (color dots in Fig. 2B, middle). This analysis resulted in 4 locations corresponding to (from top to bottom) the outer and the middle molecular layers of the suprapyramidal DG blade, and the middle and the outer molecular layers of the infrapyramidal $D G$ blade. $D S_{L}$ and $D S_{M}$ were then identified from the suprapyramidal DG blade as putative DS events with a sink occurring $\pm 25 \mu \mathrm{m}$ around the location selected in the sink histogram (solid lines in Fig. 2B, right), although average CSD profiles of classified DS events did not change when classification from infrapyramidal DG blade was used instead (dashed lines in Fig. 2B, right). Putative DS events with sinks in both the outer and middle molecular layers $(1.7 \pm 1.5 \%$; mean \pm S.D. $)$ as well as those with no sinks detected in either the outer or the middle molecular layers $(30.5 \pm 17.8 \%)$ were excluded from analyses. Only putative DS events with a sink exclusively in either the outer or the middle molecular layer $(67.8 \pm 18.3 \%)$ were classified as $D S_{L}$ and $D S_{M}$ respectively.

\section{Detection of ripple events}

We followed a previously published algorithm (Csicsvari et al., 1999) with several modifications to detect ripple events. We used the LFP recorded from the CA1 stratum pyramidale electrode, where ripples were identified visually. First, the signal was $150-300 \mathrm{~Hz}$ band-pass filtered. Next, we computed the sliding root-mean square (RMS) estimate in a 10-ms window. Next, we zscored normalized the RMS estimate and detected the local maxima with $z>3$. Finally, for each detected event, we computed the wavelet time-frequency representation of the LFP and for 
each detected event we extracted its frequency as a local peak in the time-frequency wavelet spectrum (similar to detection of gamma oscillations described earlier). Only events with frequencies between $130-250 \mathrm{~Hz}$ were selected for further analysis.

\section{Independent components analysis of the LFP}

We used independent component analysis (ICA) to extract the specific CA1 dendritic components (Fernandez-Ruiz and Herreras, 2013; Fernandez-Ruiz et al., 2017), which minimizes the impact of volume conducted signals and estimates the components that can be precisely matched to specific dendritic compartments. LFP signals that were recorded using linear silicon array electrodes were decomposed into individual dendritic components using a previously described procedure (Fernandez-Ruiz and Herreras, 2013; Fernandez-Ruiz et al., 2017; Makarov et al., 2010) with several modifications. First, LFP signals were filtered between $20 \mathrm{~Hz}$ and $150 \mathrm{~Hz}$. Next, principal component analysis (PCA) was applied to the filtered LFP data in order to find out how many principal components explain over $99 \%$ of the signal variance in the data. Next, independent component analysis (ICA) was applied to the filtered LFP data using the FastICA Matlab toolbox (Hyvarinen, 1999) by specifying the number of principal components that were obtained in the previous steps for both PCA-based dimensionality reduction and the target number of resulting independent components. Next, components of the unmixing matrix were used to compute CSDs of the individual voltage loadings for component localization and independent components (ICs) were processed using comodulogram analysis for frequency-based classification of components. Here, we took advantage of theta phase coupling of gamma oscillations, which can reveal a specific frequency footprint of each component (Schomburg et al., 2014). Specifically, the LFP from the stratum pyramidale electrode was filtered using a set of FIR filters with $2 \mathrm{~Hz}$ bandwidth, in the range $5-11 \mathrm{~Hz}$ followed by the Hilbert transform to obtain the phase of CA1 theta oscillations. Next, independent components were filtered using $20-\mathrm{Hz}$ wide filters in the range $20-150 \mathrm{~Hz}$ followed 
by the Hilbert transform to obtain amplitude information from individual components. Details of the filters and filtering procedure were described previously (Dvorak and Fenton, 2014). The phase and amplitude information were then combined between all pairs of frequency bands used to obtain phase and amplitude information and a modulation index (Tort et al., 2010) was computed for each pair resulting in a comodulogram (Figs. $3 \mathrm{C}, 5 \mathrm{~A}$ ) that reveals the peak coupling between the phase of theta and the amplitude of a given IC. We found that the ICA analysis provides better segregation of the independent components if the number of LFP channels is restricted before performing ICA. On the other hand, it is not possible to say which LFP channels to include in the analysis for best IC separation. Consequently, we performed a grid search, where we systematically repeated ICA for different numbers of included contiguous segments of LFP channels referenced either to stratum pyramidale for CA1 (Fig. 3) or to the hilus for DG (Fig. 5). The resulting CSD profiles of ICs were then visually compared and selected based on both the CSD profile of voltage loadings and a clearly isolated peak of coupling between theta phase and the amplitude of a given component. While this operation is extremely computationally intensive, it allowed robust detection of the corresponding components in all the mice we studied (Fig. S2A).

Phase locking analysis

To study the phase coupling between different oscillatory rhythms, we used the phase locking value (PLV) estimate (Lachaux et al., 1999), which provides a good estimate of phase locking for signals where the volume conducted signals have been minimized by ICA (Vinck et al., 2011). To calculate PLV of a pair of signals, we used an array of complex Morlet wavelets spaced by $1 \mathrm{~Hz}$ between $20 \mathrm{~Hz}$ and $100 \mathrm{~Hz}$ convolved with each of the ICs in the pair to obtain the instantaneous phase of both ICs at a given frequency. Next, we computed the instantaneous phase difference between the two $I C s, I C_{1}$ and $I C_{2}$. Then, for all pairs of time offsets in the range $-100 \mathrm{~ms}$ to $+100 \mathrm{~ms}$ relative to the DS event and each frequency, we 
computed instantaneous phase differences across all DS events $\Delta \varphi(t, f)=\varphi_{1}(t, f)-\varphi_{2}(t, f)$.

Finally, we computed PLV across DS events as $P L V=\frac{1}{N}\left|\sum_{n=1}^{N} \exp (i \cdot \Delta \varphi(t, f))\right|$, where $i$ is the imaginary unit, $\mathrm{N}$ is number of DS events, $\mathrm{t}$ is the offset relative to DS event and $\mathrm{f}$ is frequency used to filter the signal to obtain its phase. Repeating this algorithm for a range of frequencies and offsets relative to DS events generates a time-frequency PLV estimate that is centered at each type of DS (Fig. 5C).

\section{Detection of oscillatory cycles}

To detect oscillatory cycles of oscillatory bursts (Fig. 4), we started by correcting the polarity of ICs, because the polarity of an individual ICs is arbitrary (Hyvarinen, 1999). Here, we took advantage of the known relationship between hippocampal gamma oscillations $<100 \mathrm{~Hz}$ and the spectral leakage of spiking activity (Fig. S2B), that can be observed $>150 \mathrm{~Hz}$ at stratum pyramidale (Dvorak and Fenton, 2014; Lasztoczi and Klausberger, 2016; Schomburg et al., 2012). We first created a set of Morlet wavelets covering $20-50 \mathrm{~Hz}$ for $\mathrm{SG}_{S R}$ or covering $60-90$ $\mathrm{Hz}$ for $\mathrm{MG}_{S L M}$ and used them to obtain the instantaneous phase of the IC components at specific frequencies. Next, we filtered the LFP from stratum pyramidale in the frequency range 150-250 Hz followed by a Hilbert transform to obtain the amplitude of the high frequency activity that served as a proxy for spiking activity. Next, for each IC, we created a phase-amplitude histogram of $150-250 \mathrm{~Hz}$ amplitude distribution relative to the phase of the IC component either in the $20-50 \mathrm{~Hz}$ range or the $60-90 \mathrm{~Hz}$ range (Fig. S2B). Finally, we visually compared the resulting relationships and corrected each component so that the $150-250 \mathrm{~Hz}$ spiking-proxy activity was maximal at the descending phase of the $\mathrm{SG}_{S R}$ close to the trough and the ascending phase of $\mathrm{MG}_{S L M}$ close to the trough (Fig. S2B). This step allowed us to reliably correct the polarity of all components from all animals in order to reliably extract local minima of oscillatory bursts. After correcting the polarity of IC components, we detected oscillatory bursts 
as described earlier and then found local minima in the \pm 50 ms window around an oscillatory peak for $S G_{S R}$ and in the \pm 29 ms window around the oscillatory peak for $\mathrm{MG}_{S L M}$ corresponding to 3 cycles of oscillatory activity centered at the oscillatory cycle with largest amplitude (Fig. $\mathrm{S} 2 \mathrm{C})$. The timestamps of individual oscillatory cycles were recorded and used for later processing.

\section{Single unit analysis}

Single units were sorted using a published open-source algorithm Kilosort2 (Pachitariu et al., 2016) that is optimized for Neuropixels probes and takes advantage of GPU processing to improve algorithm performance. After automated clustering of the data, we selected only units with $<20 \%$ estimated contamination rate with spikes from other neurons that were computed from the refractory period violations relative to expected. We also excluded units with noncharacteristic or noisy waveforms resulting in identifying a total of 9404 single units.

The units were then localized to neocortex, CA1, DG/CA3 and thalamus using three criteria: 1) the depth of the Neuropixels probe relative to the cortical surface, 2) localization of dentate spikes in the hilus of dentate gyrus and sharp wave ripples in CA1 stratum pyramidale and clustering of units along the depth of the linear Neuropixels array. The clustering of units into different regions becomes apparent when we plot the depth of the maximal amplitude of the average action potential waveform for each unit along the length of the probe (Fig. S5A). The cluster of single units that overlaps with the detected location of sharp-wave ripples was classified as CA1, whereas the cluster of units that overlaps with the detected location of DS was classified as DG/CA3. The cluster of units between CA1 and the cortical surface was classified as neocortical neurons and the large amplitude units below DG/CA3 were classified as thalamic neurons. To separate CA3 from DG units, we used two additional criteria. First, we used the anatomical location, confirmed by histology, and considered CA3 units to only be from 
electrodes that were more lateral than $+1.5 \mathrm{~mm}$ relative to the midline. Second, we took advantage of the asymmetric profile of the perforant path termination in DG that is apparent in the CSD profiles of LFPs that were recorded with Neuropixels probes and triggered by DS $_{\mathrm{M}}$ events (Fig. 6B). ECII projections to the infrapyramidal molecular layers of DG terminate at the mediolateral extent at which CA3 begins, while ECII projections to the suprapyramidal molecular layers of DG continue in parallel with CA3 (Fig. 6B; Fig. S1F). Electrodes that exhibited only a dorsal current sink were classified as CA3, while electrodes that exhibited a symmetrical pair of current sinks were classified as DG. To further classify DG cells as putative granule cells (GC) and mossy cells (MC) we took advantage of two identified locations, that of the granule cell layer at the CSD reversal between the current sink in the middle molecular layer and the current source in the hilus triggered by $\mathrm{DS}_{\mathrm{M}}$, and that of the maximal amplitude of the average action potential of a given cell. Cells within $150 \mu \mathrm{m}$ of the CSD reversal were classified as GC, while cells deeper than $150 \mu \mathrm{m}$ were classified as MC (Senzai and Buzsaki, 2017). This procedure resulted in localizing 1413 cells to neocortex, 6422 neurons to thalamus, 492 cells localized to CA1, 696 cells localized to DG and 285 cells localized to CA3.

To classify units into putative excitatory and inhibitory neurons we used a similar approach as in other studies (Jia et al., 2019; Senzai and Buzsaki, 2017; Talbot et al., 2018) and extracted several features associated with the average action potential waveshape and features associated with firing properties (Fig. S5B). Datasets were split into DG cells and CA1 + CA3 cells because features of DG action potentials were visually different from those in CA1 + CA3 (Fig. S5C). Consequently, the two datasets were independently analyzed using the k-Means algorithm implemented in JMP 14 software to identify three clusters corresponding to three types of neurons classified as principal cells (E), narrow-waveform interneurons (In) and widewaveform interneurons (Iw). Classification of CA1+CA3 cells separately from DG cells led to the 
best classification results into the selected neuronal subtypes. In the analyses that follow, we only focus on $E$ and In cells because of their maximal separation in the feature space (Fig. 6A).

\section{Peri-DS-event time cofiring histogram}

We assessed the probability that a pair of cells would cofire relative to the occurrence of a dentate spike by computing a cofiring probability for each cell pair. The probability was computed in a $6 \mathrm{~ms}$-long window centered on the dentate spike peak. The co-firing probability was compared to randomly sampled events to obtain a ratio of cofiring change. Statistical validation was computed using a t test between the cofiring probabilities during DS events and randomly sampled times. The significance threshold was corrected using Bonferroni's method.

\section{Bayesian location decoding}

To obtain estimates of the mouse's location based on single unit data, we used a published algorithm (Zhang et al., 1998), where the probability of the current location is defined as $P(\boldsymbol{x} \mid \boldsymbol{n})=C(\tau, \boldsymbol{n}) P(\boldsymbol{x})\left(\prod_{i=1}^{N} f_{i}(\boldsymbol{x})^{n_{i}}\right) \exp \left(-\tau \sum_{i=1}^{N} f_{i}(\boldsymbol{x})\right)$, where $C(\tau, \boldsymbol{n})$ is a normalization factor so that $\sum_{x} P(\boldsymbol{x} \mid \boldsymbol{n})=1, f_{i}(\boldsymbol{x})$ are firing rate maps for cells $i . . N$ obtained either by binning the 2-D space into $32 \times 32$ bins (Fig. 1C) or 1-D space (distance to shock zone) into 12 angular bins (Fig. 1D), $P(\boldsymbol{x})$ is the dwell distribution, $\tau$ is the length of the time window (500 ms), $n_{i}$ is the number of spikes fired by the i-th cell in a given time window and $\boldsymbol{x}$ is the $(x, y)$ position of the animal in the $2 \mathrm{D}$ analysis or the angular position in the $1 \mathrm{D}$ analysis. Only recordings with at least five high quality spatial or non-spatial putative pyramidal cells were analyzed. Time windows with no spikes were excluded from analysis. Decoded location probability during SG $_{\text {dom }}$ (Fig. 1D) was normalized by a decoded location probability during $\mathrm{MG}_{\mathrm{dom}}\left(\mathrm{SG}_{\mathrm{dom}}\right.$ functional counterpart), computed as local peaks in the ratio of CA1 mid-frequency gamma and CA1 slow gamma). 
bioRxiv preprint doi: https://doi.org/10.1101/2020.07.20.211615; this version posted March 17, 2021. The copyright holder for this preprint (which was not certified by peer review) is the author/funder. All rights reserved. No reuse allowed without permission.

Statistical analyses were performed using JMP version 14 (SAS, Cary, NC) and Matlab 2019b (Mathworks, Natick, MA). Significance was accepted at $p<0.05$. Exact $p$ values are reported throughout. 